IFN Working Paper No. 1242, 2018

\title{
Transmission Network Investment across National Borders: The Liberalized Electricity Market
}

Lars Persson and Thomas Tangerås 


\title{
Transmission network investment across national borders: The liberalized Nordic electricity market
}

\author{
October 15, 2018
}

\author{
Lars Persson (lars.persson@ifn.se) \\ Thomas P. Tangerås (thomas.tangeras@ifn.se) \\ Research Institute of Industrial Economics \\ Grevgatan 34, P.O. Box 55665 \\ SE- 10215 Stockholm \\ Sweden
}

\begin{abstract}
The world's first multinational electricity market was formed with the creation of the Nordic power exchange, Nord Pool. We analyze the incentives to undertake transmission network investment in the context of the liberalized Nordic electricity market. Welfare improving investment in a multinational electricity market requires accounting for the cross-border effects of capacity expansion. We propose methods to increase voluntary cooperation on international infrastructure projects, with an aim to increase aggregate efficiency and achieve equitable distribution of the gains from market integration.
\end{abstract}

Keywords: Coalition formation, cross-border transmission investment, multilateral bargaining, Nordic electricity market, Shapley Value 


\section{Table of contents}

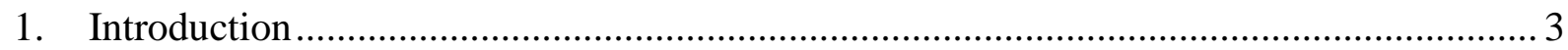

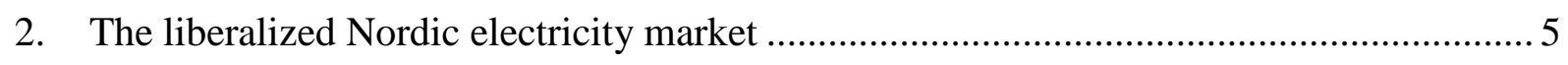

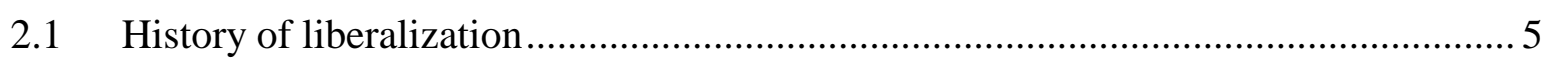

2.2 The Nordic power exchange: Nord Pool .............................................................. 7

2.3 Generation capacity in the liberalized Nordic electricity market .............................. 9

2.4 Transmission capacity in the liberalized Nordic electricity market ........................... 12

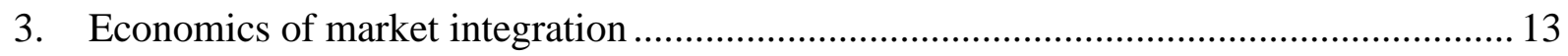

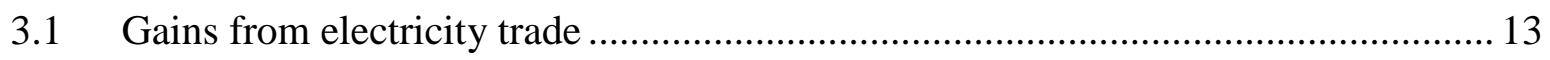

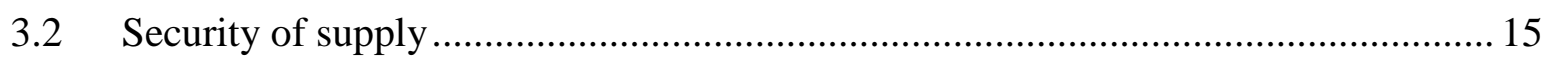

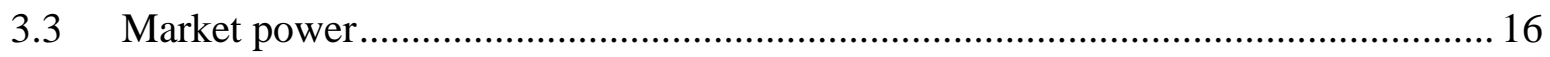

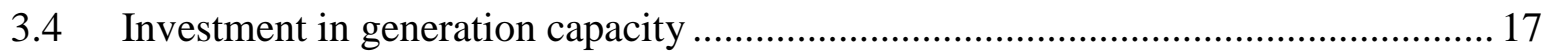

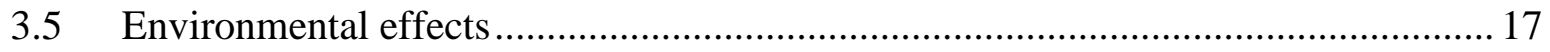

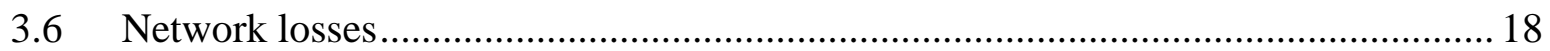

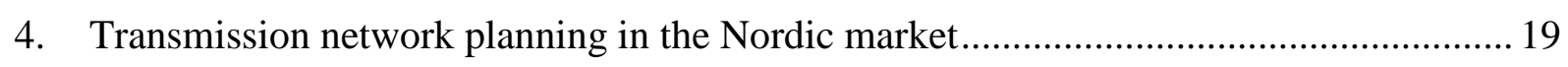

5. Incentives to undertake cross-border transmission projects ......................................... 20

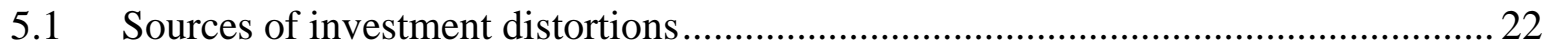

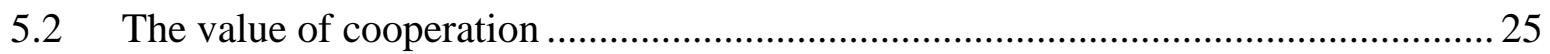

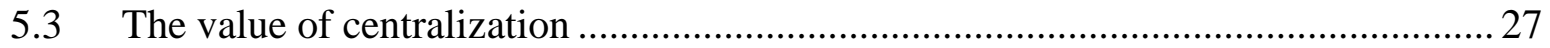

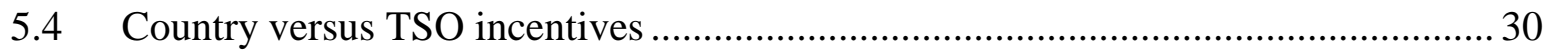

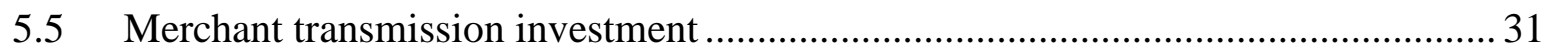

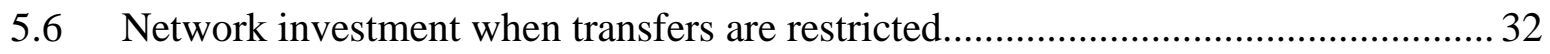

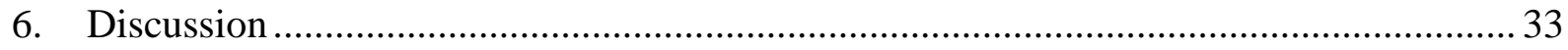

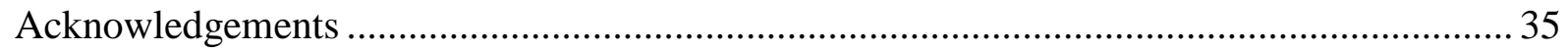

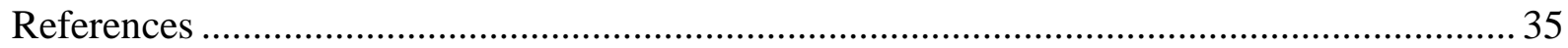




\section{Introduction}

The world's first liberalized multinational electricity market was created in 1996 when Norway and Sweden opened a power exchange for trading wholesale electricity between the two countries. Finland joined in 1998, and Denmark in 2000. The Nord Pool power exchange later expanded to incorporate also Estonia, Latvia and Lithuania, and was coupled with the North-European power market in 2014.

The backbone of the integrated market is the high-voltage transmission network that enables electricity to flow from power plants in one country to consumers in another. Figure 1 shows a map of the network infrastructure in northern Europe. In an integrated market, removal of network bottlenecks affects energy flows and prices across the entire market and therefore has implications also for surrounding counties. Welfare improving network investment requires accounting for these indirect effects of capacity expansion. This paper analyses international infrastructure investment in the context of the Nordic market.

We give in Section 2 a brief account of the historical background for liberalization of the Nordic countries. Main arguments in favor of deregulating the wholesale electricity market were to improve short-run incentives to produce electricity efficiently and create informative price signals to govern long-run investment decisions. Investments in hydro and thermal capacity have been limited the last 25 years. Possible explanations can be excess capacity and subsidies to renewable investment that have pushed down electricity prices. Most of the capacity expansion has been in renewable electricity. The picture is different for transmission network capacity, which nearly doubled the first ten years after liberalization. Congestion rent earned on interconnections has contributed to the profitability of network investment.

An important benefit of market integration in the Nordic market has been to take advantage of regional differences in the generation mix that generate gains from trade. Connecting a diverse portfolio of generation assets through a transmission network reduces the risk of supply shortages and reduces the cost of maintaining supply security. Because of geographical concentration of asset ownership, the Nordic electricity market has been vulnerable to the exercise of market power. Market power can be mitigated by network investment and market integration. Market integration reduces greenhouse gas emissions by stabilizing production and thereby reducing the need for fossil fuel generation units to handle local demand peaks. These and other main economic arguments for market integration are reviewed in Section 3.

We discuss in Section 4 transmission network planning in the Nordic market. A main driver of current investment is the transition from a hydro/nuclear based system to one with large shares of intermittent renewable electricity, which requires network reinforcement. Ambitions to export excess production and increase hydro power access to foreign markets drive integration with the rest of Europe. When calculating benefits from network expansion, TSOs emphasize gains from trade, security of supply and network losses. Gains from trade are measured on the basis of local production and consumption imbalances and the frequency with which prices differ across regions. Security of supply is measured by reserve marginsproduction and import capacity relative to peak demand. Such gains from network expansion 
Figure 1: Transmission network map for northern Europe 2018

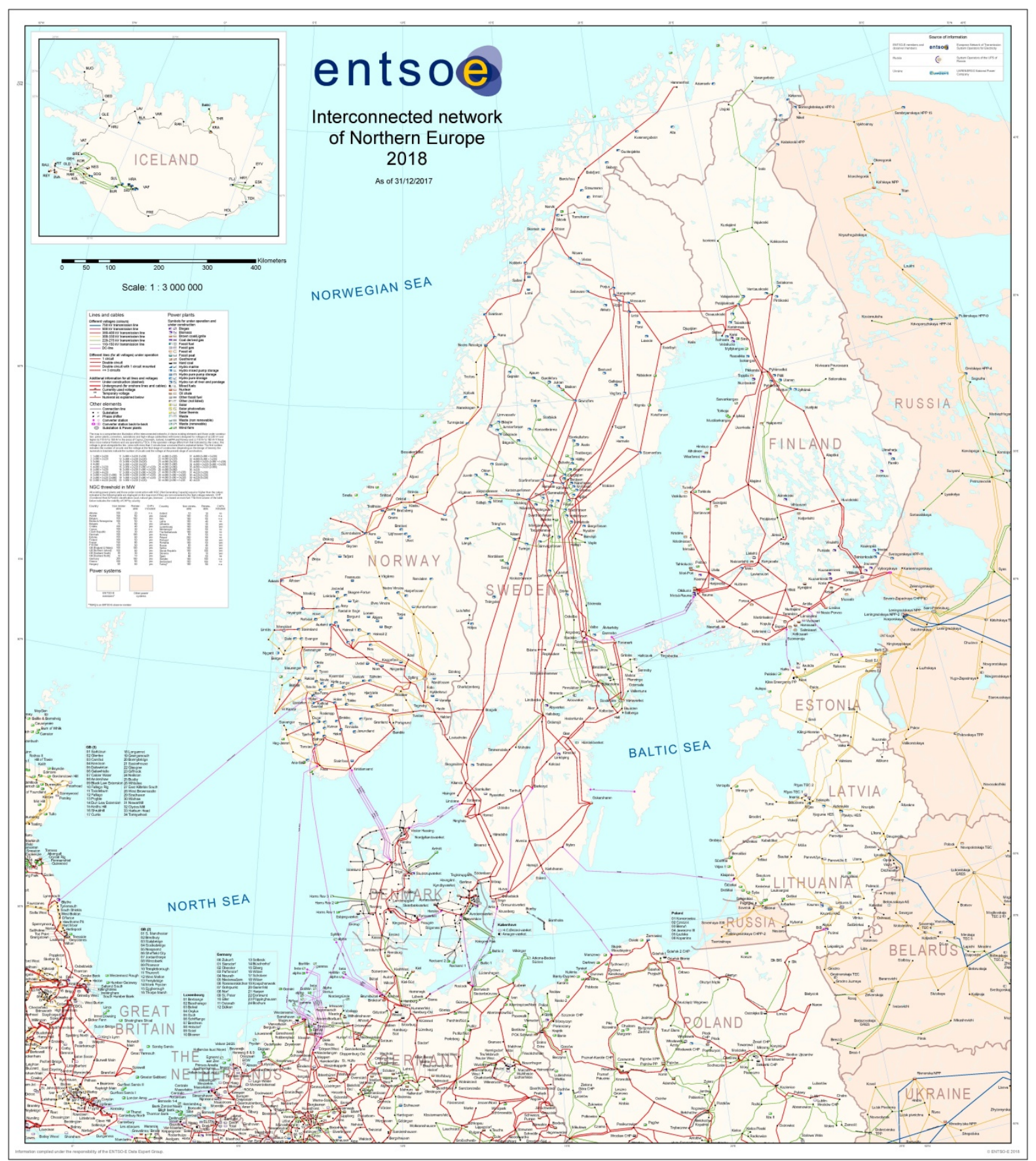

Source: www.entsoe.eu/data/map/

are in different units of measurement and therefore not directly comparable with one another, with other potentially relevant economic effects of market integration or with project costs. It is essential to apply a unified framework in which it is possible to aggregate all consequences of an expansion in network capacity, to be able to assess the full welfare economic consequences of investment.

Section 5 analyzes countries' incentives to undertake welfare increasing transmission network investment in a multinational electricity market. Investment incentives generally are distorted 
because of third-country effects, and because countries planning a project not always have an incentive to cooperate with third-party interests. Inefficiencies can persist even if countries manage to cooperate. Investments often are interrelated so that the profitability of one project depends on the (non)completion of other projects. In that case, procedural differences in how projects are decided can play a fundamental role for the outcome. Also, monopoly power can render TSO investment decisions inefficient. We discuss two approaches for increasing efficiency and ensuring countries' willingness to cooperate. Under a decentralized approach, projects originate in pairwise negotiated outcomes between the investing parties. Third-party countries can propose changes, but project modifications are voluntary. Under a centralized approach, projects are developed at the central level. Distributing surplus by the extent to which countries contribute to value creation improves incentives to participate and represents an equitable distribution of gains from market integration.

Section 6 concludes the paper with a discussion of the integrated Nordic market in relation to the political ambition of the European Union (EU) to create a well-functioning internal electricity market.

\section{The liberalized Nordic electricity market}

\subsection{History of liberalization}

Liberalization of the Nordic electricity market began with the Norwegian Energy Act of 1990 that laid the foundation for a deregulated wholesale electricity market in Norway. ${ }^{1}$ The decision to restructure the electricity market was based on an increasing discontent in Norway with the economic inefficiency of the domestic electricity system. In particular, there was no link between marginal costs of expanding production and network capacity and marginal benefits of doing so under the regulated system. Instead, capacity had been allowed to increase in an effort to supply energy intensive manufacturing industries with (for them) inexpensive electricity. These firms were on long-term supply contracts with generation companies under regulated prices that that fell short of covering long-run marginal costs of production. Households and the service industry made up for some of the difference by paying as much as four times the price of electricity paid by energy intensive industries. To achieve the desired investments, much of the capacity expansion was undertaken by the stateowned company Statkraft. There were also direct subsidies to those firms (mainly municipal) that were not state-owned.

In the regulated Norwegian market, producers had few outside options once they had fulfilled their supply obligations under the long-term contracts. For instance, producers were prevented from exporting their electricity because they did not have complete access to the high voltage transmission grid. Most of the Norwegian production is hydro power and therefore subject to random variation. When producers had nowhere to sell excess power in wet years, they ran water past the turbines. Toward the end of the 1980's annual spillage amounted to around 5 per cent of total production. Some excess electricity was exported to Denmark and Sweden,

\footnotetext{
${ }^{1}$ The historical account of Norwegian liberalization is based on Bye and Johnsen (1991), Bye and Hope (2005 and 2007) and Bredesen (2016).
} 
but at prices much below those paid by Norwegian consumers. It was obvious to many that there was scope for improvement in an electricity system that regularly threw away a resource with zero short-term marginal production cost.

Main objectives of the electricity market reform of 1990 were to: ${ }^{2}$

- Establish a platform for trading wholesale electricity in the short-term market-a power exchange-supplemented by financial markets and capacity adjustment mechanisms.

- Achieve complete and non-discriminatory access to the transmission network.

- Vertically separate the state-owned incumbent into:

0 A generation and retail unit: Statkraft

o A transmission network owner and system operator (TSO): Statnett.

- Impose regulation on network companies designed to increase economic efficiency.

The transition to a liberalized market was facilitated by the fact that Norwegian producers had already garnered experience with market-based trading platforms for short-term power before the reform took place. Already in 1972, a coalition of producers had developed Samkjøringen as a tool for reallocating electricity among themselves. Samkjøringen was a power exchange that collected bids and offers and cleared them by way of an equilibrium price. Hence, producers had already seen the benefits of market pricing of electricity. This precursor to the current spot market was insufficient because it covered only 10 per cent of annual production. The new power exchange, Statnett Marked, encompassed the entire geographical market in Norway. It was organized as a subsidiary of the Norwegian TSO, Statnett.

In Sweden, there was a consensus view that short-term gains of liberalization were small because the electricity market already operated in a cost-efficient manner. ${ }^{3}$ The concern was more with long-term efficiency: Sweden also seemed to suffer from having overinvested in production capacity. The ambition was for deregulation to deliver better price signals that would translate into more efficient investment decisions further down the road. In the beginning of the 1990s, Sweden had taken similar structural steps as Norway. For instance, vertical separation between generation and retail (Vattenfall) on the one hand, and a TSO (Svenska Kraftnät, SvK) on the other, had been accomplished by 1992. Based on the Statnett Marked power exchange, Sweden and Norway formed a jointly owned power exchange, Nord Pool, for trading wholesale electricity within and between the two countries. The world's first multinational wholesale electricity market started operation in 1996.

Finland followed suit and joined Nord Pool two years later, in 1998, and then Denmark in 2000. A main motivation for Finland to join Nord Pool was to increase efficiency and competitiveness of the energy sector. ${ }^{4}$ An interesting difference between Denmark, Finland and most other countries that deregulated, was a division of transmission network ownership prior to liberalization. In Finland, Imatran Voima (now Fortum) and Pohjolan Voima both owned substantial generation and transmission assets. As part of the restructuring of the

\footnotetext{
${ }^{2}$ Restructuring of the Norwegian electricity market did not involve privatization, unlike in the United Kingdom. See, for instance, Armstrong et al. (1994) for an overview of regulatory reform in the U.K.

${ }^{3}$ This historical account of Swedish liberalization is taken from Högselius and Kaijser (2007).

${ }^{4}$ See Pienau and Hämäläinen (2000) for an account of Finnish electricity market deregulation.
} 
industry, the two firms separated transmission from generation to create one single and jointly owned TSO, Fingrid. For those historical reasons, Fingrid has always been partially privately owned. In 2011, Fortum and Pohjolan Voima sold their shares in Fingrid to comply with EU restrictions concerning vertical ownership. The majority of Fingrid now is state-owned, with a minority share held by private companies without ownership shares in the electricity sector. Denmark originally had two transmission networks that were physically disconnected from one another. The western network covered the Jutland peninsula and was integrated with Germany. The eastern network supplied Zealand and was integrated with Sweden. The western and eastern networks were owned and operated by two companies Eltra and Elkraft System, both of which were vertically separated from generation. The two merged in 2005 to create one single TSO, Energinet.dk, owned by the Danish state. The two grids then became interconnected in 2010.

Estonia was incorporated into Nord Pool in 2010, Lithuania in 2012 and Latvia the following year. Nord Pool was then coupled with the other northern European power markets in 2014.

\subsection{The Nordic power exchange: Nord Pool}

The cornerstone of the Nordic wholesale electricity market is the power exchange, Nord Pool. The most important trading platform on the power exchange is the day-ahead market, Elspot. Elspot traded 394 terawatt hours (TWh) electricity in 2017, which amounted to 94 per cent of total production of the Nord Pool member countries. ${ }^{5}$

Elspot currently spans the Nordic countries Denmark, Finland, Norway, Sweden and the three Baltic states Estonia, Latvia, Lithuania. ${ }^{6}$ It is also coupled with the northern European power market. Elspot is divided into 15 price areas, five of which are in Norway, four are in Sweden, and two are in Denmark. The other countries comprise one price area each. The number of price areas has changed over time. Sweden, for instance, was one single price area until 2011. The Norwegian price areas have changed several times.

Every day before noon, the transmission network owners (TSOs) submit to Nord Pool for each of the 24 hours of the following day the trading capacities on the transmission lines that connect the different price areas within Nord Pool. The export and import capacities of the transmission lines from surrounding countries directly connected to Nord Pool are similarly reported. These countries are Germany, the Netherlands, Poland and Russia. Electricity producers submit offers to Nord Pool for each of the 24 hours and for every price area. Similarly, electricity retailers and large industrial consumers submit bids of how much electricity they are willing to purchase during the different hours in the different price areas. Producers are only allowed to participate in the local markets (price areas) where they have production capacity. The same is true for consumers: Retailers and industrial consumers can only participate in markets where they have consumption capacity. ${ }^{7}$

\footnotetext{
${ }^{5}$ Trading data are from the Nord Pool Annual Report 2017, which can accessed at www.nordpoolgroup.com. Production data are from www.nordpoolgroup.com/Market-data1/\#/nordic/table

6 The transmission grid of the fifth Nordic country, Iceland, is physically disconnected from all other countries' transmission networks. Iceland operates its own market.

${ }^{7}$ Virtual (convergence) bidding (Jha and Wolak, 2015) therefore is currently not allowed on Nord Pool.
} 
Transmission capacity is bid inelastically into Elspot, i.e. bids are price independent. All other market participants can submit up to 62 offers/bids for every hour and price area, specifying how much electricity they are willing to sell/purchase at different prices in each area. The price cap is 3000 Euros per megawatt hour (EUR/MWh), and bidders are allowed to submit negative prices. After gate closure of Elspot, Nord Pool combines the producer quantity/price offers by linear interpolation to generate an hourly supply curve for each of the 15 price areas. Demand curves for every hour and price area are constructed on the basis of the price/quantity bids of retailers and industrial consumers. Nord Pool then adds all area supply (demand) curves to generate an hourly system supply (demand) curve for the Nordic market. The intersection of those two curves establishes the system price. Nord Pool applies the system price to the area curves to calculate supply and demand volumes in each price area. Nord Pool then checks to see whether the resulting flows between the price areas and the import/export capacities lie within the network capacities that were supplied by the TSOs. If so, then the system price is the equilibrium price for the Elspot market that hour. Often, network capacity is insufficient to handle trade flows. Such bottlenecks occur for instance during peak hours when an increase in consumption creates excess demand in densely populated areas. Nord Pool then uses the area supply and demand curves to clear each price area separately, subject to the binding area network constraints. Hence, the Elspot equilibrium is characterized by up to 15 hourly area prices depending on the severity of network constraints. Equilibrium prices are higher in import-constrained than export-constrained areas. ${ }^{8}$

Retailers and industrial consumers (producers) pay (receive) the hourly area price for all electricity they purchase (sell) within the price area for delivery that specific hour. If there are no bottlenecks in the system, so that the system price also is the equilibrium price, then all payments and revenues balance out net of trade with countries outside Elspot. When bottlenecks occur, then consumers on Elspot pay more for the electricity they purchase than what the producers receive in compensation. The difference is the total congestion rent that is generated on Nord Pool that hour. This rent is distributed across the transmission network owners on Nord Pool depending on where in the system the congestion has occurred, the traded volumes and other factors, such as ownership.

The day-ahead market can be cleared as much as 36 hours before actual delivery, and a lot can happen that may cause market participants to want to rebalance their portfolios relative to the day-ahead allocations. To allow for such redispatch, Nord Pool operates also an intra-day market, Elbas. This market opens two hours after gate closure of the day-ahead market and closes one hour prior to physical delivery. Elbas features continuous trading and therefore essentially is a pay-as-bid market where the same product is traded at multiple prices over the course of the trading period as new market information arrives. Within the hour of delivery, the national TSOs in each of Nord Pool's member countries take over and clear actual production and consumption by way of different balancing markets.

\footnotetext{
${ }^{8}$ Nord Pool's clearing procedure implies that the supply and demand functions generally have well-defined and non-zero point elasticities, unlike in electricity markets that feature supply and demand step functions.
} 


\subsection{Generation capacity in the liberalized Nordic electricity market}

Arguments in favor of liberalization were based on the notion that generous regulation had generated excessive investment in generation and network capacity. Figure 2 shows how installed generation capacity has evolved from the start of liberalization in 1991 until 2015. The figure displays the annual capacities in megawatts (MW) aggregated over Denmark, Finland, Norway and Sweden, for the most important energy sources.

Figure 2: Installed generation capacity (MW) Nordic countries 1991-2015

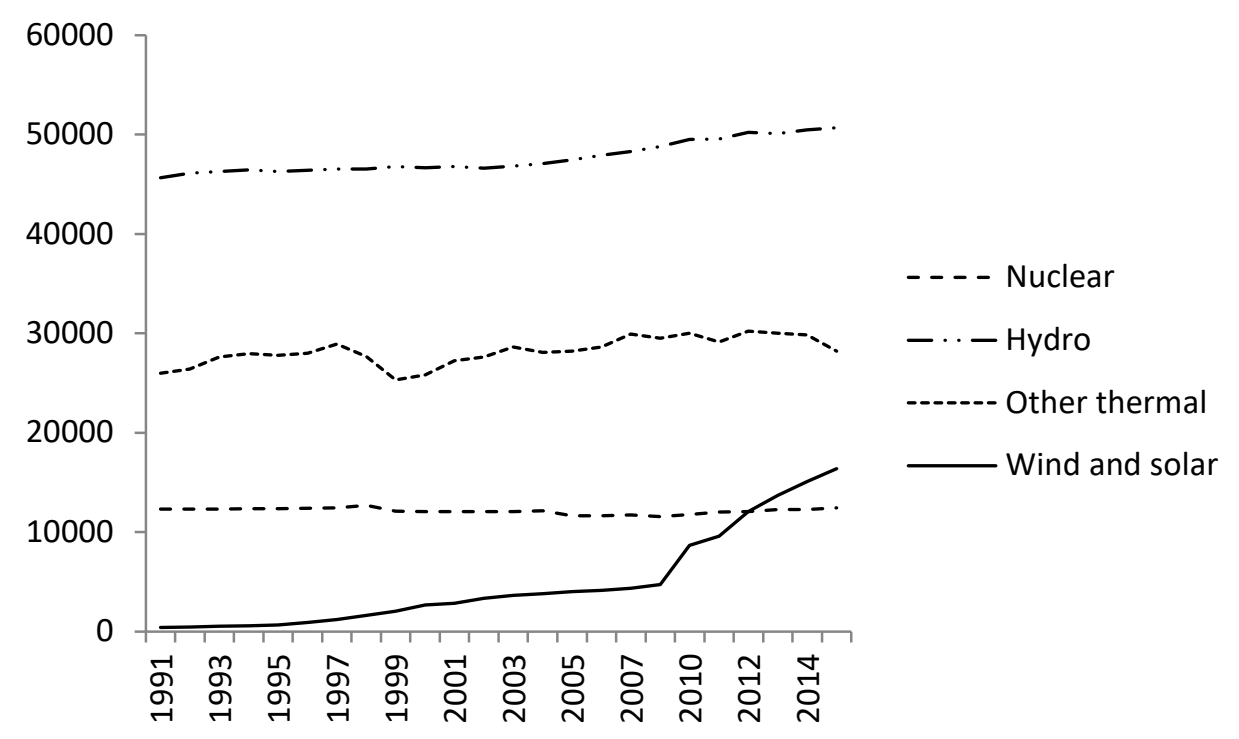

Sources: Nordel Annual Statistics 1991-2008. Data for 2010-2015 are at https://www.entsoe.eu/data/data-portal/. Year 2009 is missing.

The sum of nuclear, hydro and other thermal capacity (coal-, gas-, bio-fueled condensing power and combined heat and power plants) has remained relatively constant. Total growth over the 25 sample years was approximately 9 per cent, almost all of which occurred after year 2000. Indeed, there has been investment in hydro and thermal power, but most of it has gone into replacing decommissioned capacity. For instance, the two 600 MW Barsebäck nuclear reactors in southern Sweden represented nearly 10 per cent of total installed nuclear capacity in 1991. Both were closed by governmental decree, reactor 1 in 1999 and reactor 2 in 2005. By 2015, nuclear capacity had recovered and was slightly above the 1991 level. Two thirds of the $7400 \mathrm{MW}$ increase in non-intermittent capacity was hydro power. The picture is consistent with a story in which generation companies entered the era of deregulation with excess hydro and thermal capacity. Market prices were below the long-run cost of capital for a long period of time. Producers had to wait more than ten years for demand to catch up and capacity expansion become profitable.

Evaluating the underlying reasons why capacity has changed so little is complicated by the fact that liberalization has had effects besides exposing firms to market prices. In particular, vertical separation of generation and transmission asset ownership and the incorporation of incumbent firms created market participants on Nord Pool with market power and incentives to use it. Those incumbent firms own the majority of Nordic generation capacity even today 
(NordREG, 2014): Vattenfall (Sweden) has 19 per cent, Statkraft (Norway) 14 per cent, Fortum (Finland) 12 per cent, and Dong (Denmark) owns 6 per cent. With the purchase of Sydkraft in 2001, E.ON of Germany has been the only new large player to enter the Nordic market since deregulation, with 7 per cent of total generation capacity. Market power is accentuated by a geographical concentration of asset ownership. Vattenfall, for instance, owns 37 per cent of Swedish generation capacity. Joint ownership, in particular of Swedish nuclear power, creates additional, collective market power. Producers with market power have an incentive to withhold output to increase prices. Recent evidence based on the bidding behavior on Nord Pool suggests that firms indeed behave in such a way as to increase prices (Lundin, 2016; Lundin and Tangerås, 2017; Tangerås and Mauritzen, 2018). Firms that exercise short-term market power in general have distorted long-run incentives even to invest. Hence, liberalization has shifted the investment paradigm from one of incentives to overinvest to one of incentives to underinvest. Without further analysis, there is no way of telling whether the lack of investment has been an efficient response to price signals or an attempt by firms to drive the price of electricity up above long-run marginal cost.

The most striking feature of Figure 2 is the growth in renewable generation capacity that has occurred mainly after the turn of the millennium. Denmark was a frontrunner in the development of wind power, with production starting already in the late 1970s. A major change occurred when Sweden in 2003 became the second country in the Nordic market to launch an ambitious support system for renewable electricity. Average annual growth in solar and wind capacity has been 17.5 per cent since 1991. In 2012, solar and wind power overtook nuclear power in terms of capacity.

Figure 3: Annual renewable electricity production (TWh) in Sweden 2002-2016

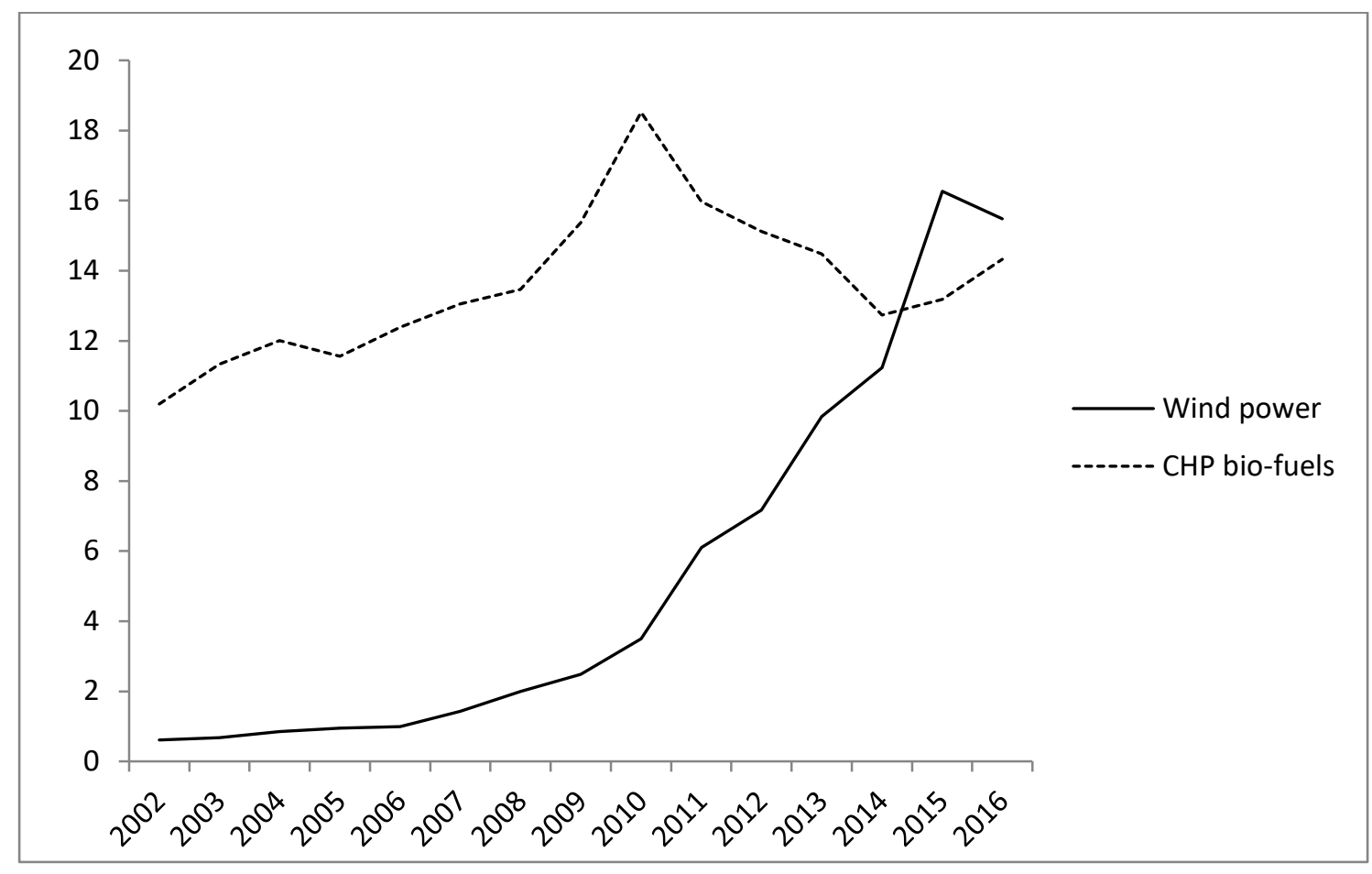

Source: Statistics Sweden (www.scb.se). 
Under the Swedish tradable green certificate system, producers earn one certificate per MWh certified renewable electricity they supply. Certificates are sold to retail companies mandated to cover a share of final consumption by renewable electricity. This additional source of revenue to the one producers earn on selling the electricity in the wholesale market, stimulate renewable investment. The certificate system was designed to be technology neutral in the sense of targeting the most cost-efficient production instead of specific technologies. In the beginning of the period, firms invested both in bio-fueled combined heat and power plants and in wind power. But after 2010, wind power has been the dominating source of new renewable capacity brought online; see Figure 3.

To develop a better understanding of the gains from liberalizing the Nordic market, and the value of transmission investment, it is important to pay attention not only to the long-run trends in energy production, but also important geographical differences across the Nordic region in how electricity is produced.

Table 1: Electricity production and consumption (TWh) in the Nordics 2015

\begin{tabular}{|l|r|r|r|r|r|}
\hline & Denmark & \multicolumn{1}{|c|}{ Finland } & \multicolumn{1}{|c|}{ Norway } & \multicolumn{1}{c|}{ Sweden } & \multicolumn{1}{c|}{ Total } \\
\hline Hydro & $<0.1$ & 16.6 & 139.0 & 74.0 & 229.6 \\
\hline Nuclear & 0.0 & 22.3 & 0.0 & 54.4 & 76.7 \\
\hline Thermal fossil fuel & 10.5 & 13.4 & 3.5 & 3.8 & 31.2 \\
\hline Thermal biofuel & 2.3 & 10.7 & 0.0 & 9.8 & 22.8 \\
\hline Solar/Wind & 14.7 & 2.3 & 2.5 & 16.6 & 36.1 \\
\hline Total & 27.5 & 65.3 & 145.0 & 158.6 & 396.4 \\
\hline Consumption & 32.4 & 82.5 & 128.3 & 135.9 & 379.1 \\
\hline
\end{tabular}

Source: ENTSO-E (www.entsoe.eu/data/data-portal/) and ENTSO-E (2015).

Table 1 shows hydro, nuclear, non-nuclear thermal and solar/wind power production and consumption measured in TWh in the four Nordic countries in 2015. Hydro power located mainly in Norway and northern Sweden is the dominating energy source and accounted for nearly 60 per cent of Nordic production. Nuclear power in Finland and southern Sweden is the second most important source with 20 per cent of production in 2015. Thermal fossil and bio-fuel condensing and combined heat and power plants in Denmark, Finland and southern Sweden accounted for 14 per cent of production. Wind power located predominantly in Denmark and Sweden has grown to become a more important source of electricity production from the early 2000s and onwards. ${ }^{9}$

The trade flows of electricity were as follows (ENTSO-E, 2015): Denmark was a net importer from Norway and Sweden and a net exporter to Germany. Finland was a net importer from Sweden and Russia and a net exporter to Estonia. Norway was a net exporter to Denmark, Sweden and the Netherlands. Sweden was a net exporter to Denmark, Finland, Germany and Poland and a net importer from Norway. Overall, the Nordic countries were net exporters of electricity in 2015.

\footnotetext{
${ }^{9}$ Notice the difference in capacity utilization between solar/wind and nuclear power.
} 


\subsection{Transmission capacity in the liberalized Nordic electricity market}

Whereas generation capacity, with the exception of wind power, has increased marginally since deregulation, the picture is completely different for transmission network capacity.

Figure 4: Installed transmission network capacity (MW) Nordic countries 1992-2008

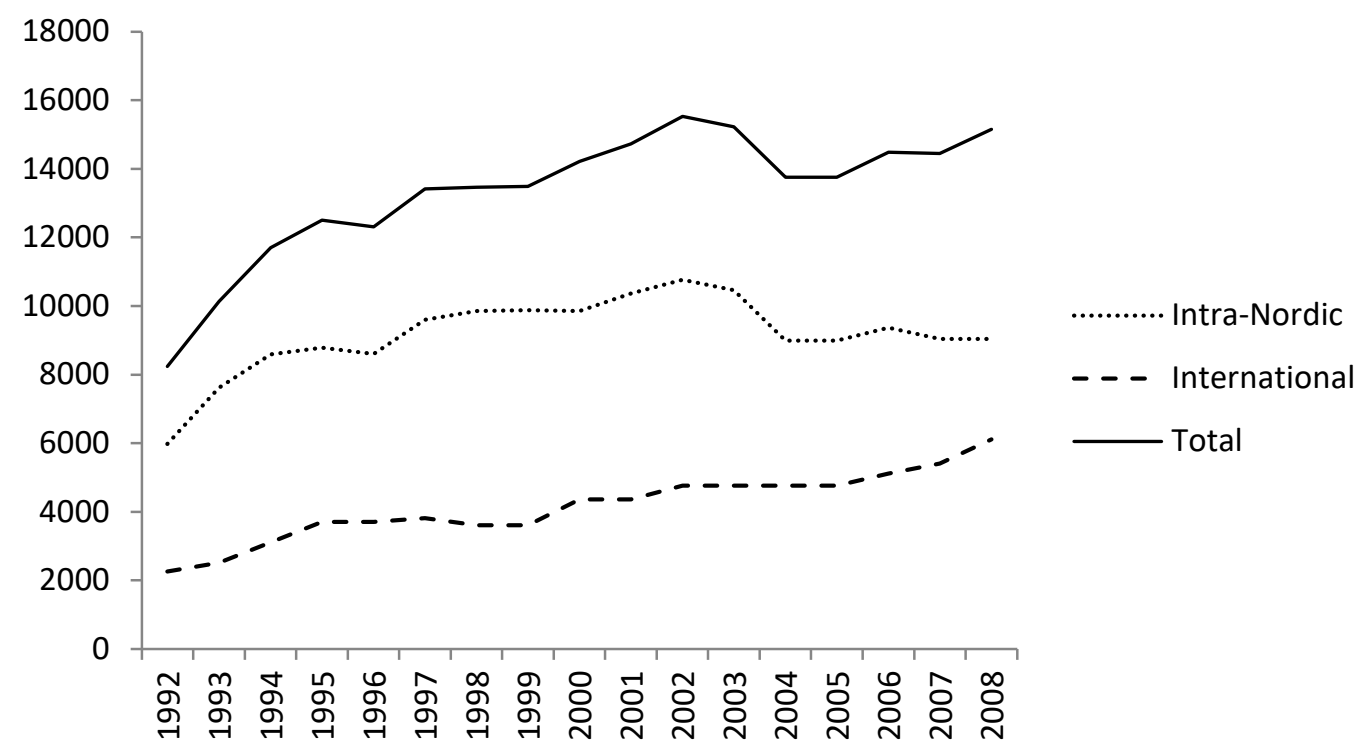

Source: Nordel Annual Reports (entsoe.eu/). Because of missing data, the 1992 international capacity is from 1991. We use the maximum of import and export capacity for individual lines, where the two differ.

Figure 4 shows how network capacity (MW) evolved between 1992 and 2008. ${ }^{10}$ The dotted line depicts the Intra-Nordic capacity, i.e. cross-border transmission capacity between the four countries Denmark, Finland, Norway and Sweden. The dip that occurred 2002-04 was temporary and due to replacement of a $300 \mathrm{kV}$ transmission line between Norway and Sweden by a $420 \mathrm{kV}$ line that required disconnection of the initial transmission line. IntraNordic transmission capacity increased by 80 per cent the first ten years after liberalization. The dashed line shows transmission capacity between the four Nordic countries and surrounding ones. International network capacity more than doubled during that period. Sweden was responsible for most of this expansion by interconnecting with Germany and Poland. Denmark almost doubled interconnection capacity with Germany, and Finland increased the import capacity from Russia. Still, the Nordic countries remain more connected with each other than with surrounding countries, measured in terms of transmission capacity. The solid line in Figure 4 is the total cross-border capacity of the Nordic market during the years 1992-2008.

Transmission capacity nearly doubled the ten years following liberalization. There could have been underinvestment in cross-border relative to domestic transmission prior to regulation that was subsequently corrected. But it is important to bear in mind that the TSOs were regulated before and after liberalization, so investment was driven by regulatory incentives even in the new market. So if capital returns to regulation were consistently high, then there was no

\footnotetext{
${ }^{10}$ Data from 2009 and onwards are currently unavailable from ENTSO-E.
} 
reason for TSOs to reduce investment after liberalization. Furthermore, deregulation of the wholesale market generated an additional source of revenue, congestion rents, that the TSOs could use to expand existing capacity and interconnect with new countries. We return to the issue of network congestion rent in Section 3.1.

\section{Economics of market integration}

A well-functioning multinational electricity market relies fundamentally on the transmission network having the capacity to transport electricity reliably and cost efficiently from power plants to consumers across the full geographical footprint of the market. This section contains an overall description of the economic benefits associated with market integration, the correct estimation of which should underlie well-informed decisions to expand capacity.

\subsection{Gains from electricity trade}

Figure 5 illustrates the direct gains from trade in the Nordic wholesale electricity market associated with an increase in cross-border transmission capacity between two countries.

Figure 5: Gains from electricity trade

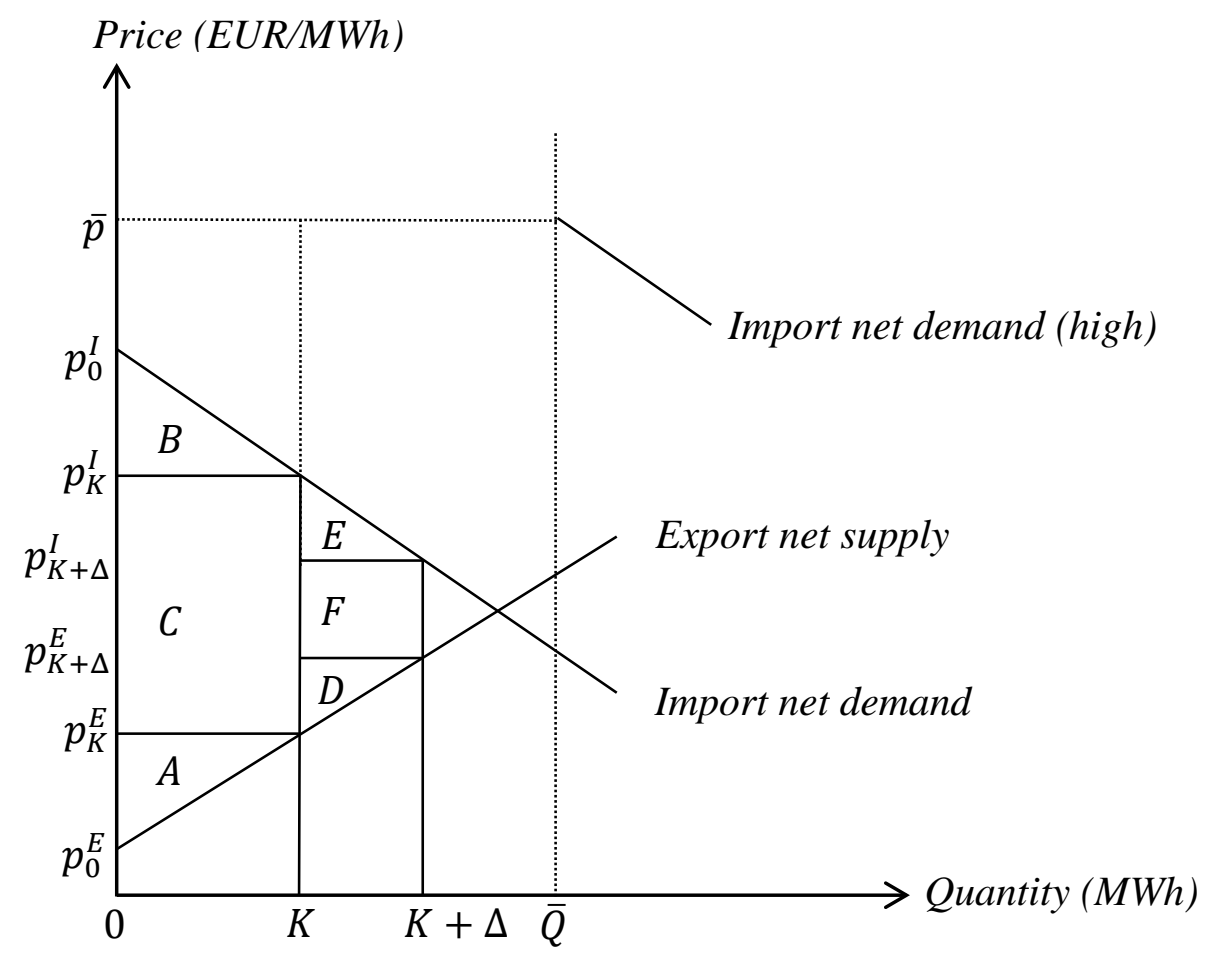

The $x$-axis shows quantities in MWhs during one hour on the day-ahead market Elspot, and the $y$-axis shows Elspot prices in EUR/MWh for that hour. The export (import) country is identified by superscript $E(I)$. The market clearing price in the export country is given by $p_{0}^{E}$ in the default situation when there is no transmission capacity between the two countries. For prices above $p_{0}^{E}$, the export country has excess supply of electricity. This domestic imbalance is increasing in the price, and is illustrated in the figure by the Export net supply curve. The market clearing price in the import country is equal to $p_{0}^{I}$ if there is no cross-country 
transmission capacity. The import country has domestic excess demand of electricity for prices below $p_{0}^{I}$, illustrated in the figure by the Import net demand curve.

For the sake of exposition, let the two countries be Denmark and Norway. Recall from Table 1 that Denmark relies heavily on wind power for domestic electricity supply. A reason why Denmark would benefit from market integration is because trade allows Denmark to import hydro power from Norway in situations with little wind in Denmark. Suppose now Denmark and Norway build a transmission line with capacity $K$ between the two countries. Norwegian producers would require a price equal to $p_{K}^{E}$ to be willing to cover both domestic demand and export $K$ to Denmark. Inexpensive hydro power from Norway causes the price in Denmark to drop down to $p_{K}^{I}$, where domestic supply and imports are just sufficient to cover domestic Danish demand. Norwegian producers benefit both from the increase in the wholesale price of electricity in Norway from $p_{0}^{E}$ to $p_{K}^{E}$ and from a net increase in output because of exports to Denmark. Conversely, the price increase and reduction in the domestic use of electricity hurt Norwegian consumers. The sum of the two is positive because Norway is a net exporter to Denmark. The increase in total consumer and producer surplus in Norway is measured by the triangle $A$ in Figure 5. Danish consumers benefit from the drop $p_{0}^{I}-p_{K}^{I}$ in the domestic wholesale price and from any resulting increase in the domestic use of electricity. Danish producers lose because of the reduction in the domestic price and because some of the domestic output is replaced by imports from Norway. The sum of consumer and producer is positive because Denmark is a net importer from Norway. The increase in total surplus in Denmark is measured by the triangle $B$ in Figure 5 . The network owner buys the $K$ MWh electricity at price $p_{K}^{E}$ in Norway and sells at price $p_{K}^{I}$ in Denmark. The rectangle $C=\left(p_{K}^{I}-\right.$ $\left.p_{K}^{E}\right) K$ measures the congestion rent of the investment. The total gains from trade this particular hour equals $A+B+C$.

There are other gains from trade than importing electricity from Norway to resolve a domestic supply shortage in Denmark. In other situations, there can be so much wind in Denmark as to create a domestic supply surplus. The cross-border connection then allows Denmark to export cheap electricity, thus enabling Norway to save hydro power for future consumption. Such trade reversal is captured in Figure 5 simply by a reinterpretation of superscripts, so that $E$ now refers to Denmark and $I$ to Norway.

Rather than increasing export possibilities from one country to the other in a uniform manner, an important benefit of market integration has been to take advantage of the geographically diverse generation mix in the Nordic market, see Table 1, which makes it easier to correct local short-term imbalances between demand and supply through cross-border trade. For instance, market integration between Norway and Denmark essentially allows Norwegian hydro power to act as a battery for Danish wind power. Offsetting local fluctuations through trade reduces the cost of equating supply and demand because the total production capacity in the market can be smaller.

There are also redistribution effects compared to when market integration essentially serves to increase trade in one direction. The benefits of market integration are better aligned between consumers and producers and across countries when trade flows go in both directions. In 
principle, consumers and producers can all benefit from improved market integration. The annual gain from trade over the cross-border interconnection between Denmark and Norway is the sum of all hourly trade surplus increases. Building an interconnection between the two countries is profitable strictly on trade terms if the total increase in trade surplus in a representative year covers the annual variable and fixed cost of the investment.

Consider now an additional investment that increases capacity even further to $K+\Delta$. The price difference in the wholesale price of electricity then falls to $p_{K+\Delta}^{I}-p_{K+\Delta}^{E}$ between the two countries. Improved market integration redistributes some of the congestion rent on the initial capacity $K$ to producers and consumers in Denmark and Norway. Net surplus in the exporting country increases by the additional triangle $D$ and by the triangle $E$ in the importing country. The change in congestion revenue equals the rectangle $F=\left(p_{K+\Delta}^{I}-p_{K+\Delta}^{E}\right) \Delta$. The increase in total trade surplus per unit of incremental capacity equals:

$$
\frac{D+E+F}{\Delta}=p_{K+\Delta}^{I}-p_{K+\Delta}^{E}+\frac{D+E}{\Delta}=p_{K}^{I}-p_{K}^{E}-\frac{p_{K}^{I}-p_{K+\Delta}^{I}+p_{K+\Delta}^{E}-p_{K}^{E}}{2} .
$$

The price differences $p_{K}^{I}-p_{K+\Delta}^{I}$ and $p_{K+\Delta}^{E}-p_{K}^{E}$ become negligible for $\Delta$ sufficiently small. It follows that the hourly trade gain from expanding cross-border capacity marginally above $K$ is approximately equal to the price difference $p_{K}^{I}-p_{K}^{E}$ between the two countries that hour. Average annual price differences thus measure the trade benefits of marginal investments in transmission capacity between local markets.

\subsection{Security of supply}

There are economic consequences of transmission network investment that cannot be captured by comparing incremental increases in spot market trade surplus with investment cost. Return to Figure 5, and let Norway be the export and Denmark the import country. Suppose Denmark has very unfavorable wind conditions and that Import net demand (high) represents the excess demand curve for electricity in Denmark. Looking at the figure, $A$ plus the congestion revenue $\left(\bar{p}-p_{K}^{E}\right) K$ appears to measure the total surplus increase associated with Denmark importing $K$ MWh electricity from Norway. But in Figure $5, \bar{p}$ is the maximal price in the Danish market. It is a regulated or implied price, not one that equates imports and domestic supply with domestic demand. Denmark has excess domestic demand $\bar{Q}-K$, even after all available domestic generation capacity and all transmission capacity has been bid into the spot market. In situations where the market fails to clear, the TSO activates capacity reserves to cover the difference $\bar{Q}-K .^{11}$ In such cases, one cannot estimate the value of transmission capacity on the basis of supply and demand curves in the spot market. Instead, the incremental benefit is the reduction in the TSO's cost of maintaining security of supply.

Figure 6 replicates the top part of Figure 5. Net demand $\bar{Q}$ is the sum of household and business demand minus the sum of wind power output and thermal capacity available to the spot market. Marginal thermal cost in Figure 6 shows the variable production cost of the

\footnotetext{
${ }^{11}$ In the terminology of Nordel (2008), a "market failure" characterizes a situation in which the day-ahead wholesale market fails to clear. A "system failure" occurs when there is insufficient physical capacity to cover demand at the delivery hour without curtailment of consumption.
} 
generation units in the domestic TSOs portfolio of capacity reserves. This reserve consists of generation capacity owned by the TSO itself plus generation capacity procured from the market. The latter are high-cost units that producers cannot profitably bid into the market given the price cap $\bar{p}$.

Figure 6: The gains from supply security

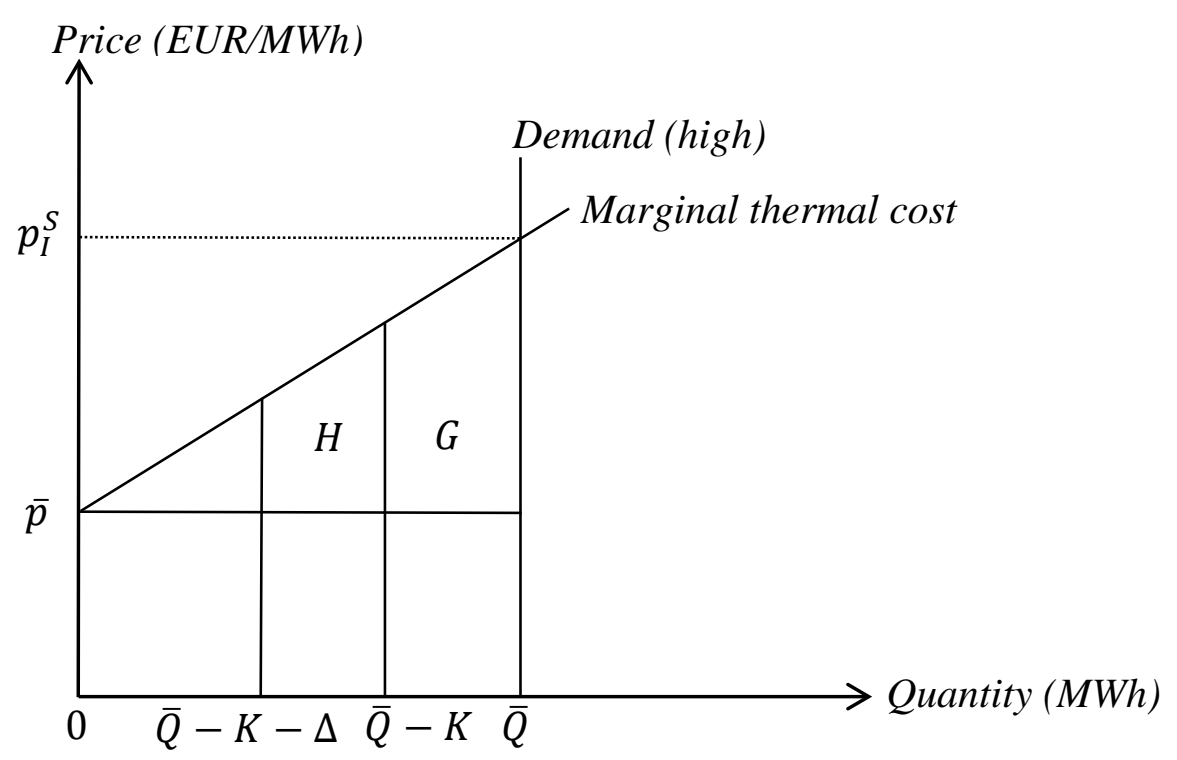

Market integration increases the security of supply in two ways. First, the likelihood of a resource constrained situation is lower because the total supply of electricity available at the price cap is higher. Second, when a resource constrained period does arise, the amount of domestic capacity reserves the TSO needs to activate is smaller when transmission capacity is larger. In Figure 6, the TSO only has to activate $\bar{Q}-K$ instead of $\bar{Q}$ when cross-border transmission capacity is $K$ instead of zero. The cost saving equals the triangle $G$, which comes in addition to the surplus in the day-ahead market. The triangle $H$ measures the incremental cost saving when additional $\Delta \mathrm{MW}$ are added to cross-border transmission capacity. In the long-run, the improved security of supply associated with market integration implies that the TSO can reduce its capacity reserve.

\subsection{Market power}

The analysis in Section 3.1 of the trade gains from market integration rests on the assumption that the wholesale markets for electricity in the two countries are competitive. Ownership of generation capacity is concentrated in the hands of a few producers in the Nordic electricity market; see Section 2.3. Hence, they have the possibility to withhold production and thereby drive up the wholesale price of electricity. Producers' exercise of market power causes two main problems for assessing the benefits of transmission investment.

Under imperfect competition, observed export net supply and import net demand curves are misrepresentations of marginal social values and social costs of consuming and producing electricity. Market power in the import country drives $p_{0}^{I}$ up above the competitive level and renders Import net demand in Figure 5 an upward-biased version of the marginal social value 
of imports. Taking the supply and demand curves at face value would then exaggerate the benefit of network investment. Market power in the export country renders Export net supply in Figure 5 an upward-biased version of the marginal social cost of export by driving the domestic price $p_{0}^{E}$ of electricity up above the competitive level. In this case, there would be underinvestment based on the supply and demand curves. With market power in both countries, the two distortions would offset one another with ambiguous net effect.

Market integration affects market performance under imperfect competition by affecting the intensity with which producers compete against one another across the two countries. An increase in competitive pressure would materialize as a downward shift in Import net demand and an upward shift in Export net supply in Figure 5. On the basis of marginal changes in trade surplus, network investment could be more or less beneficial under imperfect competition compared to the case of perfect competition. However, intensified competition would improve domestic resource allocation in both countries and thus yield an added benefit to network expansion. Under plausible circumstances, therefore, network investment is more beneficial when producers exercise market power than would otherwise be the case. However, one has to have detailed information about the extent to which firms exercise market power in the wholesale market to be able to quantify the effect on market performance of transmission network investment.

\subsection{Investment in generation capacity}

Figure 5 illustrates short-run effects of transmission network investments. In the long-run, the price changes in the electricity market affect generators' incentives to invest in capacity and industries' incentives to invest in more energy intensive production facilities. The decrease in the price from $p_{0}^{I}$ to $p_{K}^{I}$ in the import country renders it less profitable to bid generation capacity into the spot market and more profitable to expand industry production. The opposite holds in the export country. Consequently, the long-run import net demand curve lies above Import net demand in Figure 5, whereas the long-run export net demand curve is below Export net supply. Investment decisions based on the observed demand and supply curves therefore underestimate the long-run trade gains of expanding transmission network capacity. The magnitude depends on the long-run elasticities of demand and supply.

\subsection{Environmental effects}

The burning of fossil fuels for electricity and heat is the world's largest source of greenhouse gas emissions. Improved market integration has the potential to cut emissions by reducing the need for generation capacity reserves to handle local demand peaks. Reserve units often are gas-fired power plants because they must be flexible and available at short notice. But emissions reductions can also occur if market integration evens out fluctuations in production.

Figure 7 illustrates how emission of greenhouse gases (GHG, mainly $\mathrm{CO}_{2}$ ) on the $y$-axis fluctuates with electricity production from coal- and gas-fired power plants on the $x$-axis. Emissions measured in tons per MWh increase with electricity production because conversion of fossil fuels to power is less efficient at high levels of output. Assume that there is no crossborder transmission capacity between Denmark and Norway. If wind conditions are poor, then the generation companies in Denmark must dispatch a large amount $Q_{h}^{I}$ of thermal power 
to satisfy demand, which releases $G H G_{h}^{I}$ tons of greenhouse gases into the atmosphere. But if there is an abundance of wind, then only very little thermal power $Q_{l}^{I}$ has to be used in order to meet demand. Danish electricity production is nearly fossil free in this case, with emissions dropping all the way down to $G H G_{l}^{I}$. The average thermal output is equal to $Q_{a}^{I}$ and the average emissions are $G H G_{a}^{I}$.

Figure 7: Greenhouse gas emission and market integration

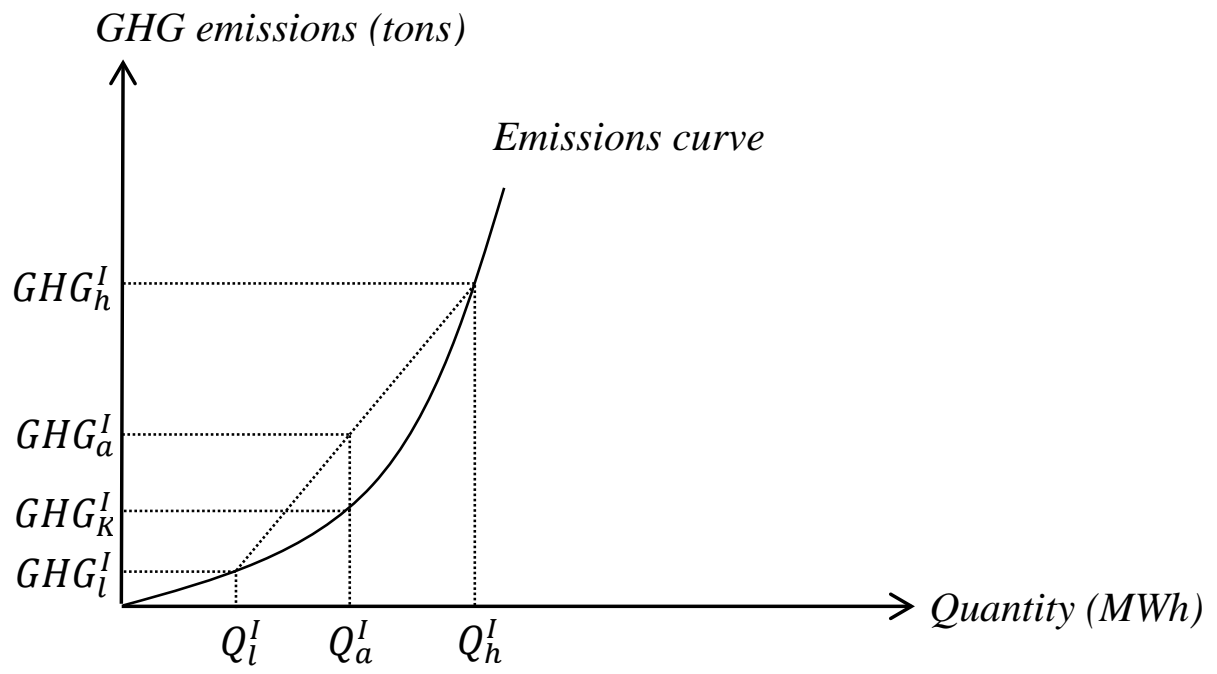

A cross-border transmission line between Denmark and Norway provides hydro power that can be used so as to even out fluctuations in wind power output. As an indirect consequence, thermal output also stabilizes across periods. Assume for the sake of presentation that thermal production is the same in both periods and equal to $Q_{a}^{I}$ when transmission capacity is equal to $K$. Although thermal production is the same before and after transmission investment, it would be incorrect to conclude that market integration had zero effect on GHG emissions. The mere fact that thermal production is stabilized drives average emissions down to $G H G_{K}^{I}$. To estimate the marginal environmental benefit of transmission investment requires a price on reducing greenhouse gas emissions. Such a price exists since the introduction of the EU-ETS trading platform for greenhouse gas emissions.

Whereas transmission network investment can have global environmental benefits in terms of reducing emissions by coal- and gas-fired power plants, there are local negative externalities for instance because of visual degradation. Efficient investment requires that local inhabitants be compensated for such damages, but they are in general difficult to quantify.

\subsection{Network losses}

Transmission of electricity across long distances leads to electrical power losses. Additional transmission capacity affects the way in which electricity flows through the entire network and therefore the total network losses. The effect of transmission on electricity transportation costs should be included in the analysis to get a picture of the full social benefit of network investment. 


\section{Transmission network planning in the Nordic market}

The Nordic TSOs apply cost-benefit analysis to identify viable transmission network investment projects within the Nordic market and to surrounding countries. A review of methods and results are found, for instance, in the Nordic Grid Master Plan 2008. ${ }^{12}$ The Nordic Grid Development Plan 2017 describes ongoing and planned future investments in the Nordic transmission network. ${ }^{13}$

A current main driver of network investment is the fundamental transformation in the Nordic generation mix that is expected to occur over the decades to come. Increased intermittent electricity production foremost in Denmark and Sweden requires network reinforcement in particular in the north-south direction in Norway and Sweden to remove domestic bottlenecks and thereby unlock hydro production from the northern part of the market. System planners envision the increase in renewable production to yield a net production surplus in the Nordic market to be exported abroad via new or improved cross-border connections to Germany from Denmark, Norway and Sweden, to Great Britain from Denmark and Norway, to the Netherlands from Denmark and to Lithuania from Sweden. Nuclear power in Finland and Sweden faces a large-scale phase out that will be partially replenished by new nuclear power in Finland at old and new locations. Increased network capacity is planned in Finland and Sweden to maintain reliability subsequent to the restructuring of Nordic nuclear power. A second driver of network investment is the need to upgrade and replace a large part of the Nordic transmission grid that was built in the 1950s and -60s. Finally, the demand for electricity is expected to grow substantially in the northernmost part of Norway with the development of Barents Sea oil fields and the electrification of oil production, which will require network capacity expansion.

Actual cost-benefit calculations begin with specifications of particularly interesting scenarios that differ from one another concerning assumptions about economic growth, fuel prices, and energy and climate policy. Based on these scenarios, projections are derived for consumer demand, generation capacity and the fuel mix in electricity generation for the following 15 to 20 years.

Cost-benefit analysis has emphasized market integration, security of supply and energy losses. Benefits of market integration are derived on the basis of the effects of network reinforcement on the system energy balance and on the market situation. The energy balance at a specific location is measured by the volume difference between annual production and consumption. The market situation is measured by the frequency with which prices between local markets differ from one another during the year. Security of supply is defined in term of the loss of load probability, which is required not to exceed $0.1 \%$ on an annual basis. In practice, security of supply is evaluated by first simulating an extreme peak demand situation-an event that occurs at most once every ten years. By comparing peak demand with installed generation, transmission and import capacity, one can then see if there is sufficient power in

\footnotetext{
${ }^{12}$ www.entsoe.eu/fileadmin/user_upload/_library/publications/nordic/planning/080300_entsoe_nordic_NordicGri dMasterPlan2008.pdf.

${ }^{13}$ The plan can be found for instance at svk.se/siteassets/om-oss/rapporter/2017/nordic-grid-development-plan2017-eng.pdf
} 
the system to satisfy local demand. The reserve margin is the difference between generation and import capacity and peak demand. The system satisfies security of supply if reserve margins are positive at all key locations. A reason why security of supply can be jeopardized is because of equipment failure, either related to the production or transmission of electricity. The Nordic market applies the $N-1$ criterion, meaning that the system should maintain full functionality even if one (near) essential unit of equipment breaks down.

In scenario analysis, it is relatively straightforward to integrate the $N-1$ reliability criterion and to calculate how new interconnections contribute to the energy balance and security of supply. But the benefits from market integration are measured in volumetric terms and/or frequencies that are not directly comparable with each other or with other important factors such as investment cost. TSOs use proprietary simulation tools to attach monetary values to the benefits of network investment. However, it is unclear how volume changes are converted and whether consumer and producer surplus effects are accounted for. Analyses account for changes in generation capacity, but treat generation investment as exogenous to network investment. Potentially relevant factors, such as market power or environmental effects, are typically ignored. Network losses typically are included in the simulation studies.

An alternative and more transparent way to estimate gains from market integration would be to use actual supply and demand curves from Nord Pool and the various short-term balancing markets. One could then recalculate market equilibria on the basis of proposed network reinforcements and thus estimate gains from trade. One way to quantify in monetary terms how a specific network project contributes to supply security would be to estimate the leastcost combination of generation and transmission capacity investment required to achieve the same reserve margin and compare this number with the investment cost of the project.

\section{Incentives to undertake cross-border transmission projects}

Consider a stylized Nordic electricity market consisting of the four countries Denmark, Finland, Norway and Sweden. Assume that there are aggregate welfare gains of improving market integration by increasing cross-border transmission network capacity. In an integrated market, removal of network bottlenecks affects energy flows and prices across the entire market and therefore has implications also for surrounding counties. Welfare maximizing network investment requires accounting also for those indirect effects of capacity expansion.

We will use elements of coalition theory to gain better understanding of incentives to, and problems associated with, carrying out international infrastructure projects in a multinational electricity market. Because of state sovereignty, no country can build a transmission line and unilaterally connect it to a foreign network. By the nature of such projects, implementation requires cooperation, specifically that countries jointly decide which projects to undertake, the technical properties of these projects and how to share investment proceeds and costs. Coalition theory deals with such cooperative decisions. The ability of involved parties to negotiate and write legally enforceable contracts renders a cooperative framework particularly 
useful. ${ }^{14}$ We will follow the approach in Horn and Persson (2001) that proposes a method to systematically compare different coalition configurations and to generate predictions about coalition formation.

A coalition structure in the Nordic market is a partitioning of the four countries into different coalitions that cooperate on cross-border network projects. A coalition structure comprises one, several or zero investment coalitions. With every coalition structure is associated a total surplus of each coalition in the structure. Each coalition consists of at least two countries, and not all countries need be part of a coalition. For instance, the coalition structure $\{D N, S, F\}$ is the one where Denmark and Norway cooperate to build a transmission line between the two countries, but Sweden and Finland cooperate with no one.

In a four-country electricity market, there are 15 potential coalition structures, not all of which are likely to occur. For instance, the coalition structure $\{D F, N, S\}$ would involve building a transmission line at the bottom of the Baltic Sea between Denmark and Finland; see Figure 1. This is probably a very expensive project. A better alternative could be to include Sweden and form the coalition $\{D F S, N\}$ and improve market integration through joint reinforcements of the Danish-Swedish and Finnish-Swedish connections. The structure $\{D F, N, S\}$ is unstable if the joint surplus of Denmark, Finland and Sweden is higher under $\{D F S, N\}$ than what they could attain under $\{D F, N, S\}$. Coalitions can be unstable also in the other direction. Consider a coalition $\{D F N, S\}$ between Denmark, Finland and Norway that involves an interconnection between northern Finland and northern Norway; see Figure 1, additional to one between Denmark and Norway. The value of a Finnish connection is limited by domestic north-south congestion in Norway that would have to be resolved. A better idea for Denmark and Norway could be to form a sub-coalition and leave Finland out of the picture by not building any line to Finland. The structure $\{D F N, S\}$ is unstable if $\{D N, F, S\}$ renders Denmark and Norway a higher joint surplus than what they could attain under $\{D F N, S\}$.

More formally, a particular coalition structure is dominated, and therefore will not occur in equilibrium, if at least one coalition in the structure is unstable either to inclusion of one or more countries in that coalition or to formation of sub-coalitions. A coalition is stable if there are no inclusions of outside countries and no formation of sub-coalitions that would increase the joint surplus of the directly involved parties. A particular coalition structure is undominated if all coalitions in the structure are stable. The set of undominated coalition structures defines the core. In the application to transmission network investment, the core identifies the different collections of transmission projects that can be implemented in equilibrium. If the core consists of only one single structure, then this coalition structure is the unique prediction of the theory. The core can consist also of multiple structures, in which case coalition theory can sustain multiple network configurations as equilibria. Finally, the core can be empty, in which case standard coalition theory has no predictions.

Gains from trade and increased security of supply probably are the most important economic effects of improving market integration of the ones categorized in Section 3 of this paper. At

\footnotetext{
${ }^{14}$ See e.g. overviews of cooperative theory in Greenberg (1994), and Osborne and Rubinstein (1994).
} 
least, those are the effects TSOs usually emphasize in their cost-benefit analyses. One might expect two TSOs negotiating over whether to build an interconnection to internalize the bilateral economic effects of the investment, provided the underlying cost-benefit analysis has been thorough and provided it lies in the two TSOs best interest to maximize the joint surplus of the two countries.

To fix ideas, suppose Denmark and Norway discuss building a new cross-border transmission line with capacity $x$ between southern Norway and western Denmark to facilitate the use of Norwegian hydro power as a battery for Danish wind power. Let $V_{i}(x)$ be the total surplus in country $i=D, N$ if the line is built, net of any congestion rent and under the assumption that the two countries each pay half of the investment cost. Assume that the cost/benefit analysis has shown the investment to be jointly welfare improving for the two countries: $V_{D}(x)+$ $V_{N}(x)>v_{D}^{0}+v_{N}^{0}$, where $v_{i}^{0}$ is the surplus of country $i$ under the status quo. Even so, it might be that one of the parties benefits a lot whereas the other loses from the investment. In coalition theory, such imbalances are overcome by reallocating congestion rent or investment cost between the two parties, or by way of compensation payments. Hence, the status quo structure $\{D, F, N, S\}$ is dominated by $\{D N, F, S\}$ in this example.

Let $T_{i}$ be the (potentially negative) compensation payment received by $i=D, N$. Let the two countries negotiate the size $x$ of the project and compensation payments $\left(T_{D}, T_{N}\right)$ to maximize the Nash product

$$
\left(V_{D}(x)+T_{D}-v_{D}^{0}\right)^{\alpha_{D}}\left(V_{N}(x)+T_{N}-v_{N}^{0}\right)^{\alpha_{N}}
$$

subject to each country $i$ 's participation constraint, $V_{i}(x)+T_{i} \geq v_{i}^{0}$, and subject to budget balance $T_{D}+T_{N}=0$. The parameter $\alpha_{i}$ measures the bargaining strength of $i=D, N$ in the negotiation. It is easy to verify that the negotiated solution is constrained efficient in the sense that the capacity $\tilde{x}$ of the transmission line is set in such a manner as to maximize the joint surplus of Denmark and Norway:

$$
V_{D}^{\prime}(\tilde{x})+V_{N}^{\prime}(\tilde{x})=0
$$

\subsection{Sources of investment distortions}

Consider third-party effects in the Denmark-Norway example. Assume that Denmark is a net importer of electricity both from Norway and Sweden; see Section 2.3. Increased market integration with Norway then causes electricity prices in Denmark to fall, which in turn reduces congestion rent earned on interconnections between Denmark and Sweden. They also lead to a reduction in wholesale prices in Sweden whenever transmission constraints do not bind. Price reductions benefit consumers, but hurt producers in Sweden. Trade surplus falls because of the country's position as a net exporter of electricity to Denmark. Hence, Sweden is likely to be worse off by the Danish-Norwegian investment, i.e. $\tilde{v}_{S}<v_{S}^{0}$, where $\tilde{v}_{S}=V_{S}(\tilde{x})$ is the total surplus in Sweden if Denmark and Norway build a cross-border transmission line with capacity $\tilde{x}$. If Sweden loses from all marginal capacity expansion, i.e. $V_{S}^{\prime}(x)<0$ for all $x>0$, then the transmission project will be excessive from the aggregate viewpoint of the three countries. 
In the above example, Sweden would lose from what it perceives to be excessive investment in cross-border connections between Denmark and Norway. Assume instead that Denmark is a net exporter to Norway, but keep everything else as before. Increased market integration then drives up the wholesale prices of electricity in Denmark to the benefit of Sweden. If $V_{S}^{\prime}(x)>0$, then the coalition structure $\{D N, F, S\}$ would yield too little investment from the joint viewpoint of Denmark, Norway and Sweden. In fact, a lack of coordination could imply that welfare improving investments might not occur at all. This can happen if investment is jointly unprofitable for Denmark and Norway, $V_{D}(x)+V_{N}(x)<v_{D}^{0}+v_{N}^{0}$ for all $x>0$, but collectively welfare improving:

$$
\sum_{i \in\{D, F, N, S\}}\left(V_{i}(x)-v_{i}^{0}\right)>0 \text {, some } x
$$

The problem here is that the pivotal countries — the ones that determine whether investment is surplus-increasing or not-are third-part countries. They are not involved in project planning and assessment unless by invitation of Denmark and Norway.

We have so far assumed that there is only one cross-border investment project. But a grid extension plan contains multiple projects. Because of the size of cross-border projects and their international effects, the incremental value of one specific project may increase or decrease depending on the extent to which other network reinforcement are undertaken. For instance, the expansion in variable renewable energy sources such as solar and wind power at the European continent has increased the value of integrating Norway with northern Europe to use Norwegian hydro power as balancing power against intermittent energy sources. One possibility is to expand Danish-Norwegian-German network capacity. Increasing cross-border capacity between Denmark and Norway is more profitable if the Danish-German line is built, and vice versa. An example where network investments are substitutes instead of complements is market integration with Great Britain. The value of the proposed $1400 \mathrm{MW}$ Viking Link connecting the Danish and British transmission systems is smaller if the Northconnect project between Great Britain and Norway is completed, and vice versa because they serve a similar purpose. Coordination problems associated with interrelated investment decisions may give rise to inefficiencies that are not always solved by forming infrastructure coalitions. Consider the following example.

Let there be four transmission projects, number one is a Norway-Sweden connection, number two is between Denmark and Sweden, number three is a Denmark-Germany connection and number four links Sweden and Germany through a cross-border interconnection. Let there be parallel coalitions: The Denmark-Germany and Norway-Sweden connections are built under structure $A=\{D G, N S\}$. Under structure $B=\{D N, G S\}$, the Denmark-Norway and GermanySweden connections are built. Assume the following surplus relations

$$
v_{D G}^{A}=v_{N S}^{A}=v^{A}, v_{D N}^{B}=v_{G S}^{B}=v^{B}>v^{A},
$$

where index $G$ refers to Germany, and $v_{i j}^{z}$ is the joint surplus of countries $i$ and $j$ under structure $z$. Structure $B$ is better from an aggregate surplus perspective than $A$. 
Assume that for coalition structures $C=\{D, G, N S\}$ and $E=\{D G, N, S\}$, the following surplus relations hold:

$$
v_{N S}^{E}>v^{A}>\max \left\{v_{N}^{0}+v_{S}^{0}, v_{D G}^{C}\right\}, v_{D G}^{E}<v_{D}^{0}+v_{G}^{0}, v_{N S}^{C}<v_{N}^{0}+v_{S}^{0} .
$$

Assume that decisions are taken sequentially. Let Norway and Sweden first decide whether to build a connection, and then Denmark and Germany decide. We solve the game by backward induction. It is optimal to build the $D G$ line in the second stage if the $N S$ line is built in the first stage because $v^{A}>v_{D G}^{C}$. But if the $N S$ line is not built in the first stage, then it is not optimal to build $D G$ in the second stage by $v_{D G}^{E}<v_{D}^{0}+v_{G}^{0}$. In the first-stage, Norway and Sweden anticipate that $D G$ is built if and only if they themselves build the $N S$ connection. Coalition structure $A$ then is the equilibrium by $v^{A}>v_{N}^{0}+v_{S}^{0}$. Now reverse the sequence of decisions. In this case, Norway and Sweden will not build the $N S$ connection either way, by $v^{A}<v_{N S}^{E}$ and $v_{N S}^{C}<v_{N}^{0}+v_{S}^{0}$. Upon realizing that Norway will not build the $N S$ line, Denmark will not build any line either by $v_{D G}^{E}<v_{D}^{0}+v_{G}^{0}$. The status quo is the equilibrium in this second case. The problem here is that Norway and Sweden are the countries that benefit the most from market integration $A$ compared to the status quo. And because of complementarities in investment decisions, they can induce Denmark and Germany to follow. For investment to come about, it is therefore essential that Norway and Sweden move first. The general insight is that reversing the order in investment decisions can fundamentally alter the equilibrium network structure in the market.

To continue the example, assume that Norway and Denmark first decide whether to build a connection and then Sweden and Germany. Under the assumptions

$$
v^{B}>\max \left\{v_{D}^{0}+v_{N}^{0} ; v_{G S}^{F}\right\}, v_{G S}^{H}<v_{G}^{0}+v_{S}^{0}
$$

for coalition structures $F=\{D N, G, S\}$ and $H=\{D, N, G S\}$, it is easy to verify that coalition structure $B$ is the equilibrium of this particular game. Hence, differences in the order in which different countries negotiate infrastructure projects can also affect the equilibrium outcome. ${ }^{15}$

The sequence of electricity market liberalization in the Nordic countries probably had an effect on the order in which transmission network investment decisions were taken. Under a different liberalization sequence, the network structure in the Nordic market perhaps would had been different than today. There is no way of knowing, and we cannot say whether the current structure is more or less efficient than what another counterfactual structure network would have been. Either way, that discussion is esoteric because liberalization is irreversible. But the above analysis points to network investments being sensitive to the decision-making process, and seemingly innocuous procedural differences can be important. Joint network planning in the Nordic electricity market therefore has the potential to increase efficiency beyond what the countries could achieve by bilateral negotiation.

\footnotetext{
${ }^{15}$ Nilssen and Sørgard (1998) consider merger formation games along these lines.
} 


\subsection{The value of cooperation}

Assume that the grand coalition $\{D F N S\}$, in which all Nordic countries cooperate on network investment, always can replicate the project portfolio of any other coalition structure, and potentially do better. Coalition theory then predicts the grand coalition to be the only equilibrium candidate because all other coalition structures are dominated (Horn and Persson, 2001). However, this result is uninformative regarding how to achieve the desired level of cooperation under voluntary participation.

Under joint decision making, all parties to a negotiation must agree to build the transmission line. The status quo prevails if at least one country vetoes the project. In other words, all participation constraints must be met for the project to go through. In the bilateral negotiation, Norway and Denmark can achieve participation through compensation payments $\left(T_{D}, T_{N}\right)$. In a joint negotiation between Denmark, Norway and Sweden, the three countries similarly negotiate $x$ and compensation payments $\left(T_{D}, T_{N}, T_{S}\right)$ to maximize the Nash product:

$$
\left(V_{D}(x)+T_{D}-v_{D}^{0}\right)^{\alpha_{D}}\left(V_{N}(x)+T_{N}-v_{N}^{0}\right)^{\alpha_{N}}\left(V_{S}(x)+T_{S}-v_{S}^{0}\right)^{\alpha_{S}}
$$

subject now also to Sweden's participation constraint $V_{S}(x)+T_{S} \geq v_{S}^{0}$ and budget balance $T_{D}+T_{N}+T_{S}=0$. The outcome of this negotiation is the efficient capacity $x^{*}$ that accounts also for the marginal effect on Sweden of increasing transmission capacity:

$$
V_{D}^{\prime}\left(x^{*}\right)+V_{N}^{\prime}\left(x^{*}\right)+V_{S}^{\prime}\left(x^{*}\right)=0 .
$$

But why would Denmark and Norway invite Sweden into the negotiation and award a third (or fourth) country veto right over the project? In our benchmark example, the negotiated transmission line has a smaller capacity than the two countries would jointly prefer: $x^{*}<\tilde{x}$. What is more, Denmark and Norway would have to pay Sweden not to veto even the modified outcome because Sweden would be better off without any additional transmission line between Denmark and Norway: $V_{S}\left(x^{*}\right)<v_{S}^{0}$ implies $T_{S}^{*}>0$ by Sweden's participation constraint. Coalition formation would not seem to work here because Denmark and Norway would rather leave Sweden outside the discussion.

The question is whether we can find rules for Nordic cooperation that would be acceptable to all parties and lead to an efficient outcome, in this case a cross-border transmission line with capacity $x^{*}$ ? Instead of vetoing the entire project, assume that each country can only veto the outcome of that specific negotiation. In particular, Denmark and Norway are free to negotiate any outcome between the two of them if joint negotiations break down. Denmark and Norway would then choose $\tilde{x}$. The default outcome, or threat point, of the three-party negotiation then changes from the status quo to $\left(\tilde{x}, \widetilde{T}_{D}, \widetilde{T}_{N}\right)$. In a joint negotiation between Denmark, Norway and Sweden, the three countries would now negotiate $x$ and compensation payments $\left(T_{D}, T_{N}, T_{S}\right)$ to maximize:

$$
\left(V_{D}(x)+T_{D}-\tilde{v}_{D}\right)^{\alpha_{D}}\left(V_{N}(x)+T_{N}-\tilde{v}_{N}\right)^{\alpha_{N}}\left(V_{S}(x)+T_{S}-\tilde{v}_{S}\right)^{\alpha_{S}}
$$

with participation constraints $V_{i}(x)+T_{i} \geq V_{i}(\tilde{x})+\widetilde{T}_{D}=\tilde{v}_{i}, i=D, N$, and $V_{S}(x)+T_{S} \geq \tilde{v}_{S}$. Even this negotiation implements the efficient investment $x^{*}$ because negotiations maximize 
the joint surplus of the involved parties. But compensation payments differ. In the negotiation, Denmark and Norway are willing to implement $x^{*}$ if and only if Sweden pays enough compensation to give the two countries a higher surplus than $\tilde{v}_{D}$ and $\tilde{v}_{N}$. Sweden would be willing to compensate both countries those required amounts to reduce capacity in the project from $\tilde{x}$ to $x^{*}{ }^{16}$

Under the modified rule for negotiations among countries, Denmark and Norway do have an incentive to invite Sweden into the negotiation because of Sweden's willingness to pay to avoid the unfavorable outcome $\tilde{x}$. One way to implement such a rule would be to allow in a first stage all countries in the Nordic market to agree on the desired cross-border investments in pairwise negotiations between the directly involved parties. When these projects are on the table, then third-parties can request renegotiation of each project, with veto right for all negotiating parties of the renegotiated solution. ${ }^{17}$

So far we have kept Finland out of the equation. There could be good reasons for doing so in our example. Assume that transmission constraints between Denmark and Sweden are always binding, both before and after the expansion to $x^{*}$ of cross-border capacity between Denmark and Norway. The only consequence for Sweden of this investment is a change in congestion rent on cross-border trade with Denmark. Transmission bottlenecks effectively isolate Finland and Sweden from the Danish and Norwegian market. Hence, electricity prices, production, consumption and trade in and between Finland and Sweden remain unchanged. Changes in the cross-border transmission capacity between Denmark and Norway have no economic consequences for Finland in this case.

Things are different in the more plausible case where transmission constraints are not always binding between Denmark and Sweden. Sweden is a net exporter of electricity to Finland; see Section 2.3. Assume for the sake of the argument that transmission capacity between Sweden and Finland is sufficiently high that the two countries always are fully integrated. Improved market integration between Denmark and Norway reduces wholesale prices in the net importing country Denmark, and by way of market integration prices in Sweden and Finland. Sweden is hurt by this price decrease, in its capacity of being a net exporter of electricity both to Denmark and Finland. Although having no direct network connections with either Denmark or Norway, Finland nevertheless experiences a positive net benefit from the investment because the country is a net importer of electricity, and market integration drives down the price of electricity in Finland. Even Finland should be allowed to participate in the planning of new transmission capacity between Denmark and Norway to ensure an efficient total outcome of the negotiations.

\footnotetext{
${ }^{16}$ To see that such compensation is feasible, let $T_{i}=\tilde{v}_{i}-V_{i}\left(x^{*}\right), i=, D, N$. Sweden's net surplus then equals $V_{S}\left(x^{*}\right)+T_{S}-\tilde{v}_{S}=V_{S}\left(x^{*}\right)-T_{D}-T_{N}-\tilde{v}_{S}=V_{D}\left(x^{*}\right)+V_{N}\left(x^{*}\right)+V_{S}\left(x^{*}\right)-V_{D}(\tilde{x})-V_{N}(\tilde{x})-V_{S}(\tilde{x})>0$.

${ }^{17}$ Could not Denmark and Norway game such rules by initially proposing a very large project just to extract a large compensation payment from Sweden? No, because a large project would not pose a credible threat point. If Sweden issued its veto right in the joint negotiations, then it would be in Denmark and Norway's joint best interest to renegotiate their initial bilateral agreement to $\left(\tilde{x}, \widetilde{T}_{D}, \widetilde{T}_{N}\right)$. Hence, $\left(\tilde{x}, \widetilde{T}_{D}, \widetilde{T}_{N}\right)$ is the only credible threat point, and all parties should rationally foresee it.
} 
The possibility that distant third-party countries are affected by the investment is not a reason to change the sequential planning structure where countries first bilaterally negotiate crossborder transmission investment and then renegotiate. Consider a joint negotiation of the crossborder line between Denmark and Norway across all four Nordic countries. Assume that the bilateral outcome $\left(\tilde{x}, \widetilde{T}_{D}, \widetilde{T}_{N}\right)$ is the default outcome. The Nash bargaining solution is the combination of $x$ and compensation payments $\left(T_{D}, T_{F}, T_{N}, T_{S}\right)$ that maximizes

$$
\left(V_{D}(x)+T_{D}-\tilde{v}_{D}\right)^{\alpha_{D}}\left(V_{F}(x)+T_{F}-\tilde{v}_{F}\right)^{\alpha_{F}}\left(V_{N}(x)+T_{N}-\tilde{v}_{N}\right)^{\alpha_{N}}\left(V_{S}(x)+T_{S}-\tilde{v}_{S}\right)^{\alpha_{S}}
$$

subject also to Finland's participation constraint, $V_{F}(x)+T_{F} \geq V_{F}(\tilde{x})=\tilde{v}_{F}$, and budget balance $T_{D}+T_{F}+T_{N}+T_{S}=0$. The multilaterally negotiated cross-border transmission capacity $x^{f b}$ between Denmark and Norway maximizes joint surplus:

$$
V_{D}^{\prime}\left(x^{f b}\right)+V_{F}^{\prime}\left(x^{f b}\right)+V_{N}^{\prime}\left(x^{f b}\right)+V_{S}^{\prime}\left(x^{f b}\right)=0 .
$$

Finland benefits from capacity expansion, $V_{F}^{\prime}(x)>0$, and Sweden loses from it, $V_{S}^{\prime}(x)<0$, so we cannot say on the basis of our current assumptions whether transmission capacity increases or decreases under renegotiation relative to the bilateral benchmark: $x^{f b} \gtreqless \tilde{x}$. Consequently, it is ambiguous whether Finland or Sweden will be net contributors of capacity payments. However, it is easy to verify that there exists a vector of compensation payments $\left(T_{D}^{f b}, T_{F}^{f b}, T_{N}^{f b}, T_{S}^{f b}\right)$ that implements the efficient investment $x^{f b}$, that transfers are budgetbalanced and render all Nordic countries weakly better off than they would have been under bilateral negotiations alone. Hence, Nordic cooperation is individually rational under the sequential procedure.

Improved market integration with continental Europe implies that investment in the Nordic network can have ramifications for a larger number of countries further south. Even the broader Nordic perspective then runs the risk of generating distorted investment incentives. As we saw above, all parties affected by an expansion of transmission capacity should be invited to participate in the negotiations for the outcome to implement a jointly efficient outcome. Negotiations between multiple interested parties are manageable when there are only a few of them, but become increasingly complicated with the inclusion of more and more parties around the table. One way to proceed would be to have transmission planning at multiple levels. First, individual countries negotiate bilateral projects. These projects are then potentially renegotiated at regional level. For instance, the Nordic market could be one such region. Then the remaining projects are lifted to the European level with final possibility for renegotiation.

\subsection{The value of centralization}

The grand coalition, which involves cooperation of all affected parties, maximizes total welfare under plausible assumptions. Section 5.2 proposed a sequential procedure that gives coalitions incentives to include additional members and then establish the grand coalition as the only possible equilibrium structure. However, the observation that there exists no other equilibrium coalition structure does not imply that the grand coalition itself is stable. Member countries that do not get enough out of the coalition can have incentive to block investment 
projects by forming sub-coalitions. There are at least two approaches to solving this problem. The first is a bottom-up approach in which countries negotiate projects in a bilateral manner and use third-country compensation payments to internalize the full effect of their decisions. The second is a top-down approach in which one tries to implement full cooperation by distributing the coalition worth, i.e. the value created by the coalition, across members in such a way as to maintain stability of the grand coalition.

To analyze third-party compensation, assume that negotiations are bilateral between Denmark and Norway. Let third-party countries $j=F, S$ receive net compensation $T_{j}=V_{j}(x)-v_{j}^{0}$. Denmark and Norway negotiate $x$ and $\left(T_{D}, T_{N}\right)$ to maximize

$$
\left(V_{D}(x)+T_{D}-v_{D}^{0}\right)^{\alpha_{D}}\left(V_{N}(x)+T_{N}-v_{N}^{0}\right)^{\alpha_{N}}
$$

subject to $V_{i}(x)+T_{i} \geq v_{i}^{0}, i=D, N$, and budget balance $T_{D}+T_{F}+T_{N}+T_{S}=0$. This solution internalizes all marginal third-party effects through the compensation mechanism and therefore implements the jointly efficient capacity $x^{f b}$.

If Denmark is a net importer of electricity both from Norway and Sweden, and Sweden is a net exporter of electricity to Finland, then Denmark, Norway and Finland would voluntarily contribute to building the interconnection, but Sweden would not. Instead, the three countries would have to compensate Sweden essentially for transiting electricity to Finland. Moreover, the marginal cost of compensation would cause Denmark and Norway to build relatively less transmission capacity. Hence, it would not be individually rational for the three countries to enter into an arrangement of third-party compensation with Sweden. As a consequence, the implemented project would be inefficient from an aggregate viewpoint.

A scope for centralization arises on the basis of the challenges associated with establishing a voluntary third-party compensation system. European Parliament (2009) contains a mechanism for compensating costs associated with cross-border flows of electricity. Compensation is to be paid to transiting countries by the countries in which the flows originate and terminate. In the example above, Denmark and Finland should compensate Sweden for transiting electricity. According to the mechanism, such costs shall be estimated on the basis of long-run average incremental costs. Benefits that a network incurs as a result of hosting cross-border flows shall be taken into account. In sum, third-party countries shall be compensated for their net cost of market integration. If country $i$ 's net cost is calculated as $T_{i}=V_{i}(x)-v_{i}^{0}$, then the investment will be efficient at the aggregate level under bilateral negotiation.

It is relatively straightforward to derive optimal compensation mechanisms for third-party countries when there is only one potential investment. Things are more complicated if there are multiple and interrelated projects. Then third-party effects depend on all project decisions. We have also shown that the order in which projects are decided can affect the equilibrium allocation and therefore third-party surplus. In such complex settings, a better approach than bilateral bargaining might be to impose in a centralized manner the solution that maximizes 
total welfare and then construct compensation payments that distribute coalition wealth in such a way as to achieve stability of the grand coalition-the top-down approach.

For a set of compensation payments to be able to sustain the fully cooperative outcome, a reasonable starting point would be to require that member countries receive a share that is positively related to the value added they contribute to the coalition. The purpose of the Shapley Value is to achieve such equitable distribution of coalition surplus.

To proceed, we let $H=\{1, \ldots, h\}$ be a coalition of $h$ countries (for instance the Nordic). There are many ways in which this coalition can form, and the contribution of each individual country $i \in H$ generally depends on the order in which it joins the coalition and which other projects have already been decided. We therefore need to calculate the expected contribution of country $i$. Let coalition $H$ form sequentially by adding one country at a time. Assume that all sequences are equally likely so that each sequence occurs with probability $1 / h$ !. The likelihood that country $i$ joins an arbitrary coalition $S \subset H$ of size $s$ equals $s !(h-s-1) ! / h$ ! because there are $s$ ! possible ways to reach coalition $S$ before player $i$ joins $S$ and there are $(h-1-s)$ ! possible ways to continue thereafter. Let $v(S)$ be the total surplus the members of coalition $S$ can achieve by cooperating given that the countries in $H$ that are not members of $S$ do not cooperate with anyone. The incremental value of adding country $i$ to coalition $S$ then equals $v(S \cup i)-v(S)$. Adding $i$ to coalition $S$ is valuable, for instance because $i$ and country $j \in S$ can decide on a cross-border interconnection once $i$ joins the coalition, but not sooner. Sum over all possible coalitions $S$ that do not contain country $i$, to get the expected contribution

$$
\varphi_{i}(v, H)=\sum_{S \in H \backslash i} \frac{s !(h-s-1) !}{h !}[v(S \cup i)-v(S)]
$$

of country $i$ to coalition $H$. This is the Shapley Value of country $i$. The Shapley value has a number of desirable properties. It distributes all the surplus of the coalition, and transfers depend on individual contributions to wealth creation, not identity. In particular, countries that do not contribute to creating wealth do not receive any of the surplus.

To visualize the Shapley Value, consider a coalition between Denmark, Norway and Germany to remove bottlenecks associated with exporting Norwegian hydro power to Germany through Denmark; see Figure 1. Countries cannot decide unilaterally to build interconnections to other countries. Therefore $v(i)=0$ for all three countries $i=D, G, N$. Assume that it would be too expensive for Germany and Norway to bypass Denmark, so that $v(G N)=0$. However, each country would unilaterally benefit from increasing market integration with Denmark, with the Danish-Norwegian connection creating a larger joint surplus to the coalition than the DanishGerman connection: $v(D N)>v(D G)$. The coalition of all three countries increases joint surplus even further: $v(H)>v(D N)$.

Applying the Shapley formula yields the following distribution of surplus in the coalition: $\varphi_{D}=\frac{1}{6}[v(D G)+v(D N)+2 v(H)]$ to Denmark, $\varphi_{G}=\frac{1}{6}[v(D G)+2(v(H)-v(D N))]$ to Germany and $\varphi_{N}=\frac{1}{6}[v(D G)+2(v(H)-v(D G))]$ to Norway. Norway gets a larger share of 
total surplus than Germany because the value of connecting with Norway is larger than the value of connecting with Germany: $\varphi_{N}-\varphi_{G}=\frac{1}{3}[v(D N)-v(D G)]>0$. Denmark obtains the largest share of surplus because of its pivotal position as a transit country that can veto all projects: $\varphi_{D}-\varphi_{N}=\frac{1}{2} v(D N)>0$.

The Shapley Value distributes most of the coalition worth to the coalition members that contribute the most to the coalition. Such a division is equitable, but is it enough to guarantee stability? In the above example, Denmark has no incentive to deviate from the grand coalition because cooperation then would completely collapse. For the same reason, Germany and Norway have no joint incentive to deviate. Germany and Norway have no unilateral incentive to deviate under the assumptions that: $v_{G}^{D N}<\varphi_{G}$ and $v_{N}^{D G}<\varphi_{N}$. It is also easy to verify that Denmark and Germany have no joint incentive to deviate if Denmark and Norway have no joint incentive to deviate. The joint net value

$$
\varphi_{D}+\varphi_{N}-v(D N)=\frac{1}{6}[4 v(H)-4 v(D N)-v(D G)]
$$

to Denmark and Norway of staying in the coalition with Germany relative to deviating and forming their own coalition, is positive if the value of building the two interconnections is sufficiently large. Kristiansen et al. (2018) simulate off-shore transmission projects in a model of the northern European electricity market and calculate associated Shapley Values. They show that the core is non-empty in their model.

The example above also shows that a Shapley Value surplus division can be unstable and seemingly unable to sustain the grand coalition. This does not exclude the possibility that there are other divisions of surplus that sustain the grand coalition. But Horn and Persson (2001) look one step ahead and require of proposed sub-coalitions that they too must be stable to pose as credible deviations. In particular, remaining members have an incentive to persuade deviators to return to the grand coalition. They have the means to do so if the grand coalition maximizes total surplus. If so, there is no credible deviation from the grand coalition.

Based upon the above arguments, there are reasons to believe that an investment coalition based on full cooperation of all countries has the potential to be stable if the grand coalition maximizes total surplus. Shapley Value surplus division might underestimate the value of some coalition members' strategic positions. One way forward to solve the predicament could be to start negotiations with calculated Shapley values as benchmarks for surplus division and then use the negotiation process to adjust compensation payments. This could be a faster process that leads to a more efficient and equitable outcome than sequential negotiations.

\subsection{Country versus TSO incentives}

The finding in Section 5.2 that negotiated outcomes maximize the total welfare of the parties to the negotiations rests on the assumption that national decision makers maximize domestic welfare. Infrastructure investment decisions are taken by the TSOs, either unilaterally (for the domestic network) or in cooperation with other TSOs (for international connections). A government believing that the TSO would always maximize domestic welfare could leave the TSO alone to act completely on its own devices. In reality, TSO operations are almost always 
under some form of government supervision and regulation. Regulation is typically imposed to curb the monopoly power of the TSO, which it could otherwise exploit to its own purposes. If there is a discrepancy between regulatory objectives and TSO incentives, one cannot presume that the unilateral or negotiated TSO investment decisions maximize either domestic or aggregate welfare with or without side payments between TSOs. How to implement efficient transmission network investment then boils down to devising and enforcing welldesigned regulatory policies for the integrated electricity market.

In the Nordic market, TSO regulation has been national in scope. With too narrow a focus on domestic effects, national regulatory agencies run the risk of ignoring externalities abroad when devising regulatory policy. Tangerås (2012) considers transmission governance in a multinational energy market.

Centralized versus decentralized regulation involves a trade-off between the benefits of internalizing cross-border externalities of market integration and coordinating network investment, on the one hand, and the risk of distorted centralized regulation, on the other. The latter occurs if, for instance, a country with little to gain from market integration exercises a dominating influence over the common regulatory policy with the result that the regulatory policy provides insufficient incentives for TSOs to improve network performance. A wellfunctioning common regulatory agency requires balancing political powers across member countries to prevent any of them from tilting the regulatory policy too far in the own direction.

Whether to collect network ownership and operations in the hands of one single TSO or to maintain multiple TSOs (recall the examples of Denmark and Finland) depends on network topology. In a radial network, the value of expanding capacity in one part of the network goes up if capacity is higher in other parts of the network. Such network complementarity increases the benefit of coordinating network investment, which speaks in favor of having one single TSO. Under a meshed network structure, the value of expanding capacity in one part of the network is lower if capacity is higher elsewhere. Under network substitutability, the benefit of coordinating network investment is smaller. Maintaining network ownership in the hands of a multiple TSOs instead increases efficiency by limiting monopoly power.

The general insight is that no single governance structure outperforms all others. The optimal governance structure depends on political factors, network structure and economic factors, for instance how the gains from energy market integration vary across countries.

\subsection{Merchant transmission investment}

The analysis has relied on an assumption that transmission investment projects are planned and executed by regulated TSOs. Indeed, most of the transmission infrastructure in the Nordic market and to neighboring countries is owned by the Nordic and neighboring TSOs. In Sweden, for instance, the current legislation requires SvK (the Swedish TSO) to hold a majority stake in all new cross-border transmission lines connected to the Swedish network. Only reinforcements of the Swedish network deemed optimal by SvK can therefore be built.

Monopoly of network ownership and coordination facilitates system operation, but has costs associated with monopoly power. A TSO can underestimate the social value of investment if 
the underlying cost-benefit analysis is incorrect, or has insufficient incentives to invest because of regulatory policy or its market power. In a situation of underinvestment, merchant investment can potentially increase market integration beyond what could be achieved under regulated monopoly. Return to Figure 5, and suppose a merchant investor contemplates the cross-border line between Denmark and Norway. The merchant only cares about congestion revenue $C$ and is likely to understate the full social value of the projects by neglecting $A$ and $B$ and uncompensated security of supply benefits. In this simplified setting, any project pursued by the merchant necessarily is socially optimal. Under plausible circumstances, therefore, merchant transmission investment can increase efficiency.

The Nordic countries have legal rules that limit who can own cross-border interconnections. Still, some of the transmission capacity that has been installed since 1992 is controlled by commercial players. The 600 MW Baltic Cable between Lübeck in Germany and Trelleborg in Sweden is owned and operated by the Norwegian generation company Statkraft. ${ }^{18}$ The 600 MW SwePol Link between Karlshamn in Sweden and the Bruskowo Wielkie power plant in Poland became operational in 2000. SwePol Link is jointly owned by SvK and the Polish TSO, PSE-Operator. The cable is operated by the Swedish generation company Vattenfall. Northconnect is a $1400 \mathrm{MW}$ cable between Norway and Scotland, with planned construction start in 2020. It is jointly owned by Vattenfall and the three Norwegian generation companies Agder Energi, E-CO and Lyse Produksjon. Another example is the $1400 \mathrm{MW}$ interconnector project NorGer between southern Norway and northern Germany. This started as a private undertaking, but now has mixed ownership with the Norwegian TSO Statnett controlling 50 per cent and Agder Energi, Lyse Produksjon and the Swiss energy trading company EGL sharing the other half.

In a compromise with the political opposition to ensure majority in the Parliament for the EU Third Energy Package, the Norwegian government decided in 2018 to disallow private ownership of international interconnectors. Consolidation of monopoly power is unfortunate on the basis of the potential efficiency gains of allowing private investment and the demonstrated private interest in developing such projects in the Nordic market.

\subsection{Network investment when transfers are restricted}

We have based the analysis on the assumption that compensation payments are sufficiently flexible to sustain investment levels that maximize joint welfare of the negotiating parties as equilibrium outcomes. Assume now that transmission investment has domestic consequences that cannot be internalized by way of transfer compensation payments. We frame the analysis around the question of how network investment contributes to security of electricity supply. ${ }^{19}$

There are two main ways how countries can protect consumers against supply shortages in the spot market. One is to reduce the risk of shortages by improving market integration. The other is for the TSO to maintain backup capacity-a strategic reserve. Network expansion is costly. Strategic reserves, by being priced outside the spot market, distort prices by driving a wedge

\footnotetext{
${ }^{18}$ Merchant ownership is not in conflict with Swedish law in this particular case because the connection began operating in 1994.

${ }^{19}$ The analysis in this section builds on Tangerås (2018).
} 
between the long-run marginal utility of consumption and the marginal cost of capacity. Costefficient security of supply is achieved at the optimal balance between market integration and capacity reserves.

Whereas network investment decisions are taken jointly by the TSOs, capacity reserves are decided at the national level. In a multinational electricity market, an increase in the capacity reserve at home has a positive externality abroad insofar as the domestic capacity is available as backup in other countries. But price distortions at home associated with a larger capacity reserve are exported abroad in an integrated market, which represents a negative externality. For any degree of market integration, a decentralized capacity decisions can imply downwardor upward-distorted capacity reserves depending whether the net foreign externality is positive or negative. Network investment and capacity reserves are strategic complements (substitutes) if the net externality is positive (negative). Market integration will therefore be insufficient. To see why, suppose strategic reserves and network capacity are at their first-best efficient levels. If the foreign net externality is positive (negative), then countries in equilibrium reduce (increase) the strategic reserve relative to the first-best. Network investment falls by complementarity (substitutability).

The lack of coordination of capacity reserves leads to downward distortions in market integration even if network investment decisions are taken to maximize the total surplus of the two countries. The problem is exacerbated if network investment decisions are uncoordinated. Absent coordination of capacity reserves, one way to increase the efficiency related to supply security, is to impose regulations that induce network owners to attach a stronger weight to the value of market integration relative to the cost of network expansion and thus overinvest all else equal. A requirement that TSOs should use most of their congestion rent to reinforce the network is an example of such a regulation.

\section{Discussion}

A main objective of EU energy policy is to develop a well-functioning internal market for electricity (Directive 2009/72/EC). Norway and Sweden took the first steps towards creating an internal Nordic market for electricity already in 1996 when they established a power exchange for trading electricity between the two countries. This market soon expanded to encompass Finland, Denmark and later the Baltic countries.

The Nordic countries realized the value of cooperation and coordinated system operation and development, in particular transmission network investment, in a joint organization, Nordel $^{20}$ Transmission network management and system operation are decentralized to the TSOs, but cooperation extends well beyond non-committed statements to improve system performance. For instance, the regulatory brief of the Swedish TSO, Svk, explicitly requires that SvK cooperates with the other Nordic TSOs to develop network projects that increase total economic welfare in the Nordic countries. Furthermore, project plans shall specify the welfare implication for each country.

\footnotetext{
${ }^{20}$ Nordel was dissolved in 2009 when the Nordic countries joined ENTSO-E, the European organization for cooperation of transmission system operators for electricity.
} 
Mutual economic benefits and an equal distribution of gains from electricity trade across countries probably have contributed to the strong commitment to market integration and robustness of the Nordic electricity market. For instance, the interconnected network has enabled Finnish and Swedish nuclear power to supply the entire Nordic market with base-load generation, which has released Norwegian and Swedish hydro power capacity for smoothing out fluctuations in net demand. A system with large amounts of hydro power stabilizes prices and reduces the need for thermal backup capacity to ensure security of supply. In particular, access to hydro power from its neighbors has allowed Denmark to develop wind power to an extent that might not otherwise have been economically feasible.

The Nordic electricity market evolved in a decentralized manner with countries volunteering to become members. Instead, the creation of a European integrated electricity market has been much more a centralized project. In other parts of Europe, the benefits of market integration have been less obvious, or the gains more asymmetrically distributed, which perhaps has contributed to a lack of devotion to the plan for an internal electricity market. We have discussed approaches to cooperation that can reinforce countries' incentives to contribute to market integration and increase efficiency. Under a bottom-up approach, cross-border projects are developed via bilateral negotiations between the directly involved parties, in a first step. Neighboring countries are then invited to propose changes in a second step, and both incumbent countries have veto rights over any modifications. This sequential procedure ensures countries' incentives to cooperate because they can always get at least as much through cooperation as from standing alone. In addition, the possibility to renegotiate gives room for efficient project alterations. Projects can be lifted to the aggregate European level for final renegotiation in a third step. Under the top-down approach, cost-benefit analysis is applied at the centralized European level to identify the portfolio of projects that is jointly optimal from a total welfare economic viewpoint. Total surplus is divided among countries on the basis of their individual contributions to value creation. While being equitable in this manner, Shapley Value surplus division could still underestimate the benefit of member countries to defect. Compensation payments may therefore have to be adjusted to meet countries’ participation constraints.

Examples from the Nordic market show that merchant transmission investment has been a viable alternative to TSO investment in cases where the latter has been reluctant to invest. For instance, merchant investors have initiated a number of cross-border infrastructure projects in Norway in periods where private ownership of interconnectors has been legal in the country. Merchant investors, by focusing on network profit alone, are likely to underestimate the aggregate economic benefits of infrastructure investment under a host of circumstances. In such cases, merchant investment is welfare improving, if allowed. From that perspective, it is regrettable that many countries severely limit the scope for merchant investment, for instance through legal barriers of entry that require TSOs to be majority owners of all cross-border interconnectors. In a situation of underinvestment and lack of cooperation on infrastructure projects, improving the business climate for merchant network investment can be a valuable complement to more centralized investment policy. 


\section{Acknowledgements}

We thank Alexandra Allard for research assistance and the Swedish Energy Agency for financial support.

\section{References}

Armstrong, Mark, Simon Cowan and John Vickers (1994): Regulatory Reform: Economic Analysis and British Experience. Cambridge, MA: MIT Press.

Bredesen, Hans-Arild (2016): The Nord Pool market model. Nord Pool Consulting, http://www.asean-aemi.org/wp-content/uploads/2016/03/AEMI-Forum-November-2015-

Bredesen-Feb2016.pdf

Bye, Torstein and Einar Hope (2005): Deregulation of electricity markets: The Norwegian experience. Economic and Political Weekly, 40, 5269-5278.

Bye, Torstein and Einar Hope (2007): Deregulering av elmarkedet-Norske erfaringer. Økonomisk Forum 1, 17-25.

Bye, Torstein and Tor Arnt Johnsen (1991): Effektivisering av kraftmarkedet.'Statistisk Sentralbyrå, Rapport 91/13.

ENTSO-E (2015). Statistical Factsheet 2015. www.entsoe.eu/publications/statistics-anddata/\#statistical-factsheet

European Parliament (2009): Regulation No 714/2009 on conditions for access to the network for cross-border exchanges in electricity. Official Journal of the European Union, L 211, 1535.

Greenberg, Joseph (1994): Coalition Structures. In: Robert J. Aumann and Sergiu Hart (eds): Handbook of Game Theory Volume 2. Amsterdam (The Netherlands): Elsevier, 1305-1337.

Horn, Henrik and Lars Persson (2001): Endogenous mergers in concentrated markets. International Journal of Industrial Organization, 19, 1213-1244.

Högselius, Per and Arne Kaijser (2007): När folkhemselen blev internationell. Stockholm: SNS Förlag.

Jha, Akshaya and Frank A. Wolak (2015): Testing for market efficiency with transaction costs: An application to financial trading in wholesale electricity markets. Manuscript, Stanford University.

Kristiansen. Martin, Francisco D. Muñoz, Shmuel Oren and Magnus Korpås (2018): A mechanism for allocating benefits and costs from transmission interconnections under cooperation: A case study of the North Sea offshore grid, unpublished manuscript.

Lundin, Erik (2016): Market power and joint ownership: Evidence from nuclear power plants in Sweden. IFN Working Paper 1113. 
Lundin, Erik and Thomas Tangerås (2017): Cournot competition in wholesale electricity markets: The Nordic power exchange, Nord Pool. IFN Working Paper 1191.

Nilssen, Tore and Sørgard, Lars (1998): Sequential horizontal mergers. European Economic Review, 42, 1683-1702.

Nordel (2008): Nordic Grid Master Plan 2008. www.entsoe.eu/fileadmin/user_upload/_library/publications/nordic/planning/080300_entsoe nordic_NordicGridMasterPlan2008.pdf

NordREG (2014): Nordic Market Report 2014. Report 4/2014.

Osborne, Martin J. and Ariel Rubinstein (1994): A Course in Game Theory. Cambridge, MA: MIT Press.

Pineau, Pierre-Olivier and Raimo P. Hämäläinen (2000): A perspective on the restructuring of the Finnish electricity market. Energy Policy, 28, 181-192.

Tangerås, Thomas (2012): Optimal transmission regulation of an integrated energy market. Energy Economics, 34, 1644-1655.

Tangerås, Thomas (2018): Equilibrium supply security in a multinational electricity market with renewable generation. Energy Economics, 72, 416-435.

Tangerås, Thomas and Johannes Mauritzen (2018): Real-time versus day-ahead market power in a hydro-based electricity market. Journal of Industrial Economics, forthcoming. 